\title{
Alfay, editor y compilador: de las Poesías varias (1654) a las Delicias de Apolo (1670)
}

\author{
Rocío JodAR JURAdo \\ Universidad de Sevilla
}

Título: Alfay, editor y compilador: de las Poesías varias (1654) a las Delicias de Apolo (1670).

Resumen: El presente trabajo estudia la génesis y doble publicación de las Delicias de Apolo, una de las principales antologías poéticas del siglo XVII. Además de abordar la doble paternidad de la obra a cargo de José Alfay y Francisco de la Torre, se analizan distintos aspectos relacionados con la bibliografía material que arrojan luz sobre la composición de este volumen.
Title: Alfay, Editor and Compiler from the Poesias varias (1654) to the Delicias de Apolo (1670).

Abstract: This article studies the genesis and double publication of the Delicias de Apolo, one of the most important poetic anthologies of the XVIIth. In addition to the research of the double authorship of the anthology by Francisco de la Torre and José Alfay, we also offer an analysis of different issues related to material bibliography, which helps to understand the composition of this volume.

Key words: Delicias de Apolo, Alfay, Francisco de la Torre, Baroque, Poetry.

Date of Receipt: 2/4/2019.

Date of Approval: 11/5/2019.

\section{El quehacer editorial de José Alfay Ballur}

A la hora de estudiar una antología - al igual que cualquier otro libro- debemos tener en cuenta una serie de avatares históricos, codicológicos, estéticos, mercantiles o culturales, entre otros, que condicionan su nacimiento, composición y posterior distribución. No en vano, la escritura y la práctica editorial siempre han estado ligadas, pues estas últimas afectan al proceso de composición de las obras. Como observara Ricardo Morales, "el escritor 
escribe para ser leído"'; por lo que para la concepción de su obra es lógico, sobre todo a partir de la introducción de la imprenta en España, que baraje criterios estéticos y pragmáticos que influyen en la elaboración de sus textos y en su posterior ordenación, con el objeto de transmitir un mensaje descodificable $^{2}$. En este proceso se cifra una de las preocupaciones más hondas del autor, toda vez que publica un volumen como suyo. En palabras de Ruiz Pérez,

la edición representa la última composición del texto: aquella en la que recibe su forma definitiva y es preparado para su difusión y recepción. Los humanistas ya se habían ejercitado en esta labor con textos ajenos, y su práctica actualizó a la vez las obras de los clásicos y la importancia de un ejercicio de mediación de enorme trascendencia en la institucionalización de la literatura. La extensión de esta práctica acabó incorporándola la labor poética, como una fase más, la definitiva, avanzando sobre la recomendación horaciana de lima, pues esta se limita al pulimiento del poema para acercarlo a su forma perfecta, en tanto que la edición apunta a la fijación, ne varietur, que le asegura al poeta la relación de propiedad con su texto ${ }^{3}$.

1 José Ricardo Morales, Las artes de la vida: la arquitectura y el drama, suplemento de Anthropos, 35 (1992), p. 150.

2 Como apunta Ignacio García Aguilar, Imprenta y literatura en el Siglo de Oro. La poesía de Lope de Vega, Madrid, Ediciones del Orto, 2006, pp. 16-17, partiendo de una perspectiva inmanentista, es común "utilizar el término texto de acuerdo con las acepciones fijadas por las teorías de la lingüística moderna” y, en consecuencia, olvidar "el componente material que determina la socialización de lo escrito". Por ello, es importante recordar que "el texto impreso que recibimos como lectores no deja de ser, en cierto modo, un tapiz hecho a varias manos. Esto obliga, por tanto, a discernir entre lo propio del editor, de las marcas institucionales del orden legal o mercantil y, por supuesto, de la intención del escritor, quien también se vale de las posibilidades materiales del libro para instrumentalizarlo y ponerlo al servicio de su particular poética compositiva, así como de sus aspiraciones de fama y celebridad". Roger Chartier, "Del libro a la lectura. Lectores «populares» en el Renacimiento", Bulletin Hispanique, IC, 1 (1997), pp. 309-324 (p. 316), también incide en el componente material del libro y afirma que "contra la abstracción del texto, hay que recordar que la forma que lo da a leer participa también en la construcción del sentido. El «mismo» texto, fijado en su letra, no es el mismo si cambian los dispositivos del objeto o de la forma de comunicación que lo transmite a sus lectores, a sus oyentes, o a sus espectadores".

3 Pedro Ruiz Pérez, La rúbrica del poeta. La expresión de la autoconciencia poética de Boscán a Góngora, Valladolid, Universidad de Valladolid, 2009, pp. 290-291. 
Es sabido que cuando un poeta muere sin publicar su obra, circunstancia nada infrecuente en el Siglo de Oro ${ }^{4}$, surgen numerosos problemas. Baste recordar como ejemplos paradigmáticos la edición póstuma de las obras de Garcilaso a cargo de la viuda de Boscán (Las obras de Boscán y algunas de Garcilaso de la Vega, 1543) o la intrincadísima circulación de la poesía de Quevedo:

4 Como apuntó Antonio Rodríguez Moñino, Poesía y cancioneros (siglo XVI), Madrid, Artes Gráficas Soler S. A., 1968, p. 20, "ningún contemporáneo riguroso pudo leer, reunidas en conjunto y dadas a conocer por la imprenta, las [obras] de los escritores de primera categoría [...]. Las obras de todos ellos o se imprimen póstumamente, a veces dos o tres siglos después de que sus autores han muerto, o aún no han visto la luz pública: así sucede con Liñán de Riaza, Francisco de Garay, Marco Antonio de Vega, Burguillos, Juan Bautista de Vivar, Pedro Rodríguez de Ardilla, por mencionar solamente algunos de los que tuvieron extraordinaria fama y popularidad”. Además, subraya el gran bibliólogo la escasa difusión del libro de poesía en esta época, por lo que concluye que "los impresos, pues, no pudieron ser la fuente de un conocimiento amplio, por parte de los contemporáneos, tal como lo son para el lector de hoy". Véase Antonio Rodríguez Moñino, "Construcción crítica y realidad histórica en la poesía española de los siglos XVI y XVII", en Estudios y ensayos de literatura hispánica de los Siglos de Oro, ed. Víctor Infantes, Cáceres, Genueve Ediciones, 2010, pp. 47-82 (p. 60). Esto no resultará extraño si consideramos que a menudo la poesía se difundía por medio de la venta ambulante: "así sucede, por ejemplo, con los romances, dados a leer (y cantar) en la forma doble de pliegos sueltos", tal como apunta Roger Chartier, op. cit., pp. 312-313.

5 Es de sobra conocida la importancia de la labor editorial realizada por dońa Ana Girón de Rebolledo, así como por el impresor Carles Amorós: "La primera [...] mostraba en el espacio del volumen una curiosa transformación, entre cuyos estadios se contaban la dimensión de personaje de los poemas, al que se alude, por ejemplo, en la epístola a Diego Hurtado de Mendoza, la de eje del cancionero amoroso ordenado en el libro II al modo de Petrarca, la de esposa sustituta funcional de la Laura de las Rime in morte y, finalmente, la de colaboradora en el proyecto editorial (y no solo poético) de su marido, sin que nos sea posible saber si esto ya era así antes de que este accediera a la condición de difunto. En cuanto a Carles Amorós, no debió ser ajena su intervención a los aspectos de la edición tocantes a su diseño gráfico, como la adopción de un formato, el cuarto, que acabaría convirtiéndose en distintivo de los impresos poéticos de cierto fuste y de una letrería redondilla que era la primera evidencia de una separación de los modelos poéticos ligados a los tipos góticos, prácticamente barridos del espacio gráfico de los impresos poéticos cultos una década después". Véase Pedro Ruiz Pérez, "Las obras de Boscán y Garcilaso: modelo editorial y modelo poético”, Caliope, XIII, 1 (2007), pp. 15-44 (pp. 17-18). Asimismo, no es 
Si la transmisión poética española constituye siempre [...] un apasionante capítulo hasta de sociología literaria, la transmisión de la obra quevedesca es, sin ninguna duda, el más complicado que conoce no solo nuestra historia literaria, sino la europea desde el Renacimiento hasta hoy ${ }^{6}$.

Y es que, según el propio Blecua,

podría escribirse un precioso volumen de introducción a la crítica textual solo con los problemas que la transmisión de la obra quevedesca plantea a cualquier editor de hoy. Le saldrán al paso correcciones autógrafas que no deberá dar por definitivas, correcciones de editores, piraterías editoriales, transmisiones manuscritas, impresas y cantadas, atribuciones falsas y hasta peregrinas, etc ${ }^{7}$.

Estos problemas se acentúan cuando es el editor quien, con fines comerciales y, tal vez, con alguna aspiración estética, decide compilar y luego estampar una antología en la que se recogen textos dispares de varios autores y que, como es natural, persigue unos beneficios más o menos pingües. A continuación, abordaremos la composición de las Delicias de Apolo por parte de José Alfay, partiendo de la base de que su diseño no es aleatorio, sino que obedece a una serie de motivos artísticos y, sobre todo, mercantiles bien definidos por su responsable.

Durante el Seiscientos, el sector editorial gozaba de uno de sus momentos de esplendor tras la introducción de la imprenta en nuestro país:

A lo largo del siglo XVII la edición de obras impresas conoció un notable auge; se cuentan por miles el número de obras que franqueaban los pasos intermedios y lograban salvar su original estado manuscrito para convertirse en un texto impreso ${ }^{8}$.

descartable tampoco la intervención editorial del librero Joan Bagés, movido "por el interés comercial, como no podía ser de otra forma" (Ibidem, p. 17).

6 José Manuel Blecua, "Introducción” a Francisco de Quevedo y Villegas, Obra poética, Madrid, Castalia, 1999, p. XI.

7 Ibidem, p. XI.

8 David González Ramírez, "José Alfay, librero, editor y compilador de Zaragoza. 
Dicha ebullición resultó especialmente significativa en Zaragoza, donde las circunstancias políticas espolearon sobremanera la práctica poética como afirmación de la identidad del reino aragonés:

Entre los vínculos con Castilla y el trono, de una parte, y, de otra, la presión resultante de la revuelta catalana, aún tras el retorno de sus protagonistas a la disciplina del trono, la capital zaragozana vive con intensidad la búsqueda para formular o redefinir su propia identidad, en un momento en el que, además, se está produciendo una amplia y profunda fractura, desde el modelo epistemológico a la manifestación estética que aunamos bajo el rótulo de Barroco. Con los polos de las élites locales y la corte virreinal, la práctica poética o, en términos más amplios y exactos, el ejercicio del verso discurre entre las pervivencias de los modelos académicos, la afirmación de círculos cultos de nuevo cuño y la emergencia de formas ligadas al desarrollo comercial. De ello dan cuenta, respectivamente, el auge de justas y certámenes, junto a la proliferación de círculos poéticos de cierta regularidad, donde se aúnan la consolidación social, la visibilidad del poder y el protagonismo de las élites; la proliferación de textualizaciones de la efectiva realidad de los grupos culturales y poéticos [...]; y, finalmente, la actividad de Alfay en su compleja dimensión de impresor, librero y promotor de antologías?.

Así las cosas, a lo largo de la Edad de Oro,

Zaragoza tiene, pues, la exclusiva (digamos) de las obras aragonesas, que son muchísimas en número; pero tiene además la gloria de haber dado algunas ediciones príncipes y otras [ediciones] repetidas de literatura general ${ }^{10}$.

Catálogo comentado de las obras publicadas a su costa”, Archivo de Filología Aragonesa, 66 (2010), pp. 97-154 (p. 99).

9 Pedro Ruiz Pérez, "La edición zaragozana a mediados del siglo XVII y la sistematización del libro de poesía”, Bulletin Hispanique, 113 (2011), pp. 69-101 (pp. 70-71).

10 Gerónimo Borao, La imprenta en Zaragoza, Zaragoza, Vicente Martínez Tejero, 1995, p. 27. 
Una de las principales figuras de este círculo, José Alfay Ballur, nació en Zaragoza durante el reinado de Felipe IV. Fue hijo del librero Pedro Alfay, de quien heredaría su profesión, y de Ana Ballur, mas quedó huérfano de madre durante su infancia, por lo que su abuela materna ejerció como tutora suya y de su hermano Miguel Gregorio. La familia vivió a lo largo de estos años en unas casitas en la Platería, donde se encontraba la librería regentada por la familia. En 1632 falleció su abuela, y solo algunos años más tarde, antes de 1640, su hermano Gregorio Miguel, por lo que Alfay heredó 4000 sueldos procedentes de la dote de su madre. Contrajo matrimonio el 3 de septiembre de 1646 con Francisca Teresa Nuin y, tan solo un año más tarde, se asentó en la plaza de las Estrébedes, antigua calle de Escuelas Pías, por la que hoy pasa la Avenida César Augusto. Tras alcanzar el grado de maestro librero en 1646, a su cargo se publicaron las Experiencias de amor y fortuna, de Francisco de Quintana (1647); las Tragedias de amor, de Juan de Arce Solórceno (1647); las Novelas amorosas de los mejores ingenios de España (1648 y 1649), al cuidado del propio Alfay; la Sala de recreación, de Castillo Solórzano (1649), que apareció póstuma ${ }^{11}$; las Poesías varias de grandes ingenios españoles (1654); La Perla. Proverbios morales, de Alonso de Barros (1656 y 1664); el Bureo de las musas, de Jacinto Polo de Medina (1659); las Carnestolendas de Toledo, de Antolínez de Piedrabuena (1661); la Mojiganga del gusto en seis novelas y estorbo de vicios, del apócrifo Francisco de la Cueva (1662); el Sarao de Aranjuez, resultado de los viejos remanentes que tenía de la Mojiganga del gusto, que se estampó en Madrid con datos falseados (1666); y las Delicias de Apolo, colectánea publicada simultáneamente en Madrid, bajo el cuidado de Francisco de la Torre ${ }^{12}$, y en Zaragoza, respaldada por el propio Alfay $(1670)^{13}$.

11 David González Ramírez, "Sobre la princeps de dos textos póstumos de Castillo Solórzano: Sala de recreación y La quinta de Laura", en Novela corta y teatro en el Barroco español (1613-1685). Studia in honorem Prof. Anthony Close, eds. Rafael Bonilla Cerezo, José Ramón Trujillo y Begońa Rodríguez, Madrid, Sial Ediciones, 2012, pp. 55-75 (pp. 57-59).

12 Sobre las relaciones entre José Alfay y Francisco de la Torre, véase Manuel Alvar, "D. Francisco de la Torre, amigo de Calderón”, Revista de Filología Española, 31 (1947), pp. 155-161 (pp. 156-157).

13 Sobre la edición y publicación de las Delicias de Apolo, véase Esperanza Velasco de la Peña, Impresores y libreros en Zaragoza (1600-1650), Zaragoza, Instituto Fernando 
Alfay parece gustar de la composición editorial de florilegios; verbigracia las Novelas amorosas, "una taracea de textos plagiados que fueron atribuidos a un autor irreal" 14, y la Mojiganga del gusto y el Sarao de Aranjuez, títulos nacidos ambas de un fraude editorial:

En 1662 sale de la imprenta de Juan de Ibar una obra titulada Mojiganga del gusto en seis novelas y estorbo de vicios, cuyo autor decía ser un tal Francisco de La Cueva. Con esta colección Alfay filtró una superchería literaria en la que plagió seis textos procedentes de la Guia y avisos de forasteros, del Guzmán de Alfarache y Guzmán el Bravo (novela de Lope incluida en La Circe, con otras rimas y prosas). El mercader de libros zaragozano le colocó a la colección un título original y le asignó un autor ficticio. Hasta el momento ningún editor había intentado parejo fraude literario. Unos años más tarde, llevó presuntamente al mismo taller tipográfico unos preliminares nuevos que fueron acomodados al cuerpo en el que se imprimieron algunos años antes las seis novelas expoliadas; en la portada de estos rezaba un nuevo título, Sarao de Aranjuez, y su autor, natural de Madrid, según indicaba falsamente el frontispicio, era Jacinto de Ayala ${ }^{15}$.

Las Poesias varias de grandes ingenios españoles y las Delicias de Apolo fueron, sin duda, sus principales antologías. Los puntos en común entre ambas son más que notables, destacando el cruce de nombres en las portadas y dedicatorias, que suscitan dudas sobre la autoría final. Aun cuando Alfay costeó la publicación de dichas obras,

la responsabilidad de la compilación [de las Poesías varias] fue puesta en entredicho por A. Coster, quien, a partir de una carta copiada por Latassa y fechada en 1654, creía probable que el autor de $E l$ Criticón fuera "le compilateur [...] dédié à Francisco de la Torre". Esta opinión fue seguida por Arco y Garay, y reforzada algunos años más tarde por Miguel Romera-Navarro ${ }^{16}$.

el Católico, 1998, pp. 307-309 y Miguel Romera-Navarro, "La antología de Alfay y Baltasar Gracián”, Hispanic Review, XV, 3 (1947), pp. 325-345 (p. 342).

14 David González Ramírez, "Introducción" a Francisco de La Cueva y Jacinto de Ayala, Mojiganga del gusto y Sarao de Aranjuez, Zaragoza, Larumbe, 2010, p. XIX.

15 Ibidem, pp. XIV-XV.

16 David González Ramírez, "José Alfay, librero, editor y compilador de Zaragoza. 
No obstante, Rozas se mostró contrario a esta hipótesis, pues caso de aceptar la posibilidad de "que Gracián, como tantos eruditos de todos los tiempos, se haya visto en la obligación interesada de ayudar a un editor o librero" ${ }^{17}$, el prólogo de la antología, presuntamente redactado por el aragonés, no es más que "una solemne exculpación, ante el lector selecto, de un libro que no lo es"18. Por tanto, Gracián intervendría en las Poesías varias

como un gourmet que quiere adornar un plato que no le gusta. Pudo aportar algunos consejos en la confección, pudo incluso hacer el breve prólogo. Pero este muestra, más allá de toda captatio, un desacuerdo entre el paladar del que lo redacta y los manjares que allí se ofrecen. El libro se hizo como un negocio, buscando textos que pudiesen ser leídos por un amplio público, casi de pliego de cordel en algunos momentos ${ }^{19}$.

A Alfay y Gracián se suma el poeta Francisco de la Torre para conectar este par de libros, siendo este último el destinatario de la dedicatoria de las Poesías varias, cuya firma aparece incluso en el prólogo de uno de los testimonios conservados ${ }^{20} \mathrm{y}$, según la edición madrileña de las Delicias de Apolo, sobre la que discurrimos, el responsable de este volumen. Si conforme a las fechas de aprobación y publicación de las Delicias de Apolo aceptamos que la edición madrileña de la obra respaldada por

Catálogo comentado de las obras publicadas a su costa”, p. 116. Remitimos aquí también a los trabajos de Miguel Romera-Navarro, "La antología de Alfay y Baltasar Gracián”, op. cit., y “Dos aprobaciones de Gracián”, Hispanic Review, VIII, 3 (1940), pp. 257-263; así como a los de Ricardo del Arco y Garay, La erudición aragonesa en el siglo XVII en torno a Lastanosa, Madrid, Imprenta Góngora, 1934, p. 151, y La erudición española en el siglo XVII y el cronista de Aragón Andrés de Ustarroz, Madrid, CSIC, 1950.

17 Juan Manuel Rozas, "El compromiso moral en la Agudeza (y en las Poesías varias de Alfay)", en Gracián y su época. Actas de la I Reunión de Filólogos Aragoneses, Zaragoza, Institución de Fernando el Católico, 1986, pp. 191-200 (p. 199).

18 Ibidem, p. 199.

19 Ibidem, p. 200.

20 Se trata del ejemplar que perteneció a Agustín Durán, conservado en la BNE: R-6848. 
Francisco de la Torre sería anterior a la zaragozana y que, en consecuencia, le debemos su diseño, la intervención de Alfay se reduciría notablemente. No obstante, la incorporación de una dedicatoria al VI duque de Alba en la edición aragonesa delata lo contrario, pues, como es sabido, don Fernando Álvarez de Toledo falleció el 7 de octubre de 1667. Por tanto, entre las páginas de las Delicias se deslizan las piezas de un puzle que nos ayudará a reconstruir el arduo proceso de elaboración de esta antología.

2. Diseño y Composición de las Delicias DE APOLO: PROBlemas Materiales

A diferencia del cuidado que el librero zaragozano dispensó a su primera colectánea, las Delicias de Apolo sobresalen por su descuido formal. Por ello, conviene describir los ejemplares que han llegado hasta nosotros, aquilatando las singularidades de cada uno de ellos:

Ejemplares conservados en la Biblioteca Nacional de España

a) Madrid

Delicias de Apolo, recreaciones del Parnaso por las tres musas Vrania, Euterpe y Caliope: hechas de varias poesias de los mejores ingenios de España

Alegre, Melchor fl. 1665-1671 imp.

R/6821

1670

[8], 177, [11]. La última página, correspondiente al "Soneto al serenísimo don Juan de Austria”, no está numerada y así aparece en todos los ejemplares. Se insertan 5 hojas más sin paginar al final del volumen, cuya disposición oscila según el ejemplar.

Carece de grabados.

Carece de la portada de la musa Urania.

Procedencia: "Librería Licenciado D. Cayetano Alberto de la Barrera". 
Delicias de Apolo, recreaciones del Parnaso por las tres musas Vrania, Euterpe y Caliope: hechas de varias poesias de los mejores ingenios de España

Alegre, Melchor fl. 1665-1671 imp.

2/8100

1670

[8], 174, [10], 175-177, [1]. Las cinco hojas sin paginar se insertan entre las páginas 174 y 175.

Carece de grabados.

Delicias de Apolo, recreaciones del Parnaso por las tres musas Vrania, Euterpe y Caliope: hechas de varias poesias de los mejores ingenios de España

Alegre, Melchor fl. 1665-1671 imp.

8/30886

[12], 174, [10], 175-177, [1]. Las cinco hojas sin paginar se insertan entre las páginas 174 y 175 . El ejemplar incluye la aprobación de José del Calvo y Monreal, que corresponde a la edición zaragozana. Carece de grabados

b) Zaragoza

Delicias de Apolo, recreaciones del Parnaso por las tres musas Vrania, Euterpe y Caliope: hechas de varias poesias de los mejores ingenios de España Ibar, Juan de imp.

$\mathrm{R} / 3056$

1670

[10], 177, [11]. Las cinco hojas sin paginar se insertan al final del volumen. Falto de $2 \mathrm{~h}$. de preliminares correspondientes a la aprobación. Incluye $1 \mathrm{~h}$. (antep. de la musa Urania) que pertenece a la edición de Madrid.

El ejemplar presenta varios grabados: el blasón de don Fernando de Toledo, el grabado acerca de la musa Urania y el correspondiente a la musa Euterpe. El grabado relativo a la musa Calíope ha sido arrancado.

Encuadernación tardía (probablemente del siglo XVIII) en pasta española. 
Procedencia: Biblioteca Real.

Ejemplar reproducido en línea: http://bdh-rd.bne.es/viewer. vm?id=0000079418\&page $=1$

Delicias de Apolo, recreaciones del Parnaso por las tres musas Vrania, Euterpe y Caliope: hechas de varias poesias de los mejores ingenios de España

Ibar, Juan de imp.

$\mathrm{R} / 8135$

1670

[12], 174, [2], 175-177, [1]. Se trata de un ejemplar mútilo. Conserva únicamente una de las cinco hojas sin paginar, correspondiente al cuaderno Y (Y4r-Y4v).

Carece de grabados.

Carece de la portada de la musa Urania.

Delicias de Apolo, recreaciones del Parnaso por las tres musas Vrania, Euterpe y Caliope: hechas de varias poesias de los mejores ingenios de España

Ibar, Juan de imp.

$\mathrm{R} / 2733$

1670

[12], 174, [10], 175-177, [1]. Las cinco hojas sin paginar se insertan entre las páginas 174 y 175.

Carece de grabados.

Carece de la portada de la musa Urania.

Delicias de Apolo, recreaciones del Parnaso por las tres musas Vrania, Euterpe y Caliope: hechas de varias poesias de los mejores ingenios de España Ibar, Juan de imp.

$8 / 20909$

1670

[8], 174, [10], 175-177, [1]. Ejemplar incompleto. Faltan dos hojas de los preliminares correspondientes a la aprobación. Las cinco hojas sin paginar se insertan entre las páginas 174 y 175.

Carece de grabados. 
Ejemplar conservado en la Biblioteca Provincial de Córdoba

Delicias de Apolo, recreaciones del Parnaso por las tres musas Vrania, Euterpe y Caliope: hechas de varias poesias de los mejores ingenios de Zaragoza, España

Ibar, Juan de imp.

$4-158$

1670

[12], 174, [10], 175-177, [1]. Las cinco hojas sin paginar se insertan entre las páginas 174 y 175.

Posee un único grabado: el blasón de don Fernando de Toledo.

\section{Ejemplar conservado en la Biblioteca Zabálburu}

Delicias de Apolo, recreaciones del Parnaso por las tres musas Vrania, Euterpe y Caliope: hechas de varias poesias de los mejores ingenios de Madrid, España

Alegre, Melchor fl. 1665-1671 imp.

1670

[8], 174, [10], 175-177, [1]. Las cinco hojas sin paginar se insertan entre las páginas 174 y 175.

Carece de grabados.

\section{Ejemplar conservado en la Biblioteca de la Real Academia Española}

Delicias de Apolo, recreaciones del Parnaso por las tres musas Vrania, Euterpe y Caliope: hechas de varias poesias de los mejores ingenios de Zaragoza, España

Ibar, Juan de imp.

RAE RM - 6740

[12], 174, [10], 175-177, [1]. Las cinco hojas sin paginar se insertan entre las páginas 174 y 175.

El ejemplar conserva varios grabados: el blasón de don Fernando de Toledo, el grabado perteneciente a la musa Urania y el correspondiente a la musa Euterpe. 


\section{Ejemplares conservados en la Biblioteca Valenciana Nicolau Primitiu}

Delicias de Apolo, recreaciones del Parnaso por las tres musas Vranía, Euterpe y Caliope: hechas de varias poesias de los mejores ingenios de España

Alegre, Melchor fl. 1665-1671 imp.

XVII/1072 DIGITAL

[8], 174, [10], 175-177, [1]. Las cinco hojas sin paginar se insertan entre las páginas 174 y 175.

Carece de grabados.

Delicias de Apolo, recreaciones del Parnaso por las tres musas Vranía, Euterpe y Caliope: hechas de varias poesias de los mejores ingenios de España

Alegre, Melchor fl. 1665-1671 imp.

$\underline{\text { XVII/1072 }}$

[8], [10], 1-177, [1]. Las cinco hojas sin paginar se insertan tras los preliminares.

Ejemplar guillotinado para su reencuadernación.

Carece de grabados.

\section{Ejemplar conservado Biblioteca Municipal Serrano Morales, Valencia}

Delicias de Apolo, recreaciones del Parnaso por las tres musas Vrania, Euterpe y Caliope: hechas de varias poesias de los mejores ingenios de España

Alegre, Melchor fl. 1665-1671 imp. $3 / 66(2)$

[8], 174, [10], 175-177, [1]. Las cinco hojas sin paginar se insertan entre las páginas 174 y 175.

Carece de grabados. Ex libris ms. de Onofre Esquerdo. 


\section{EJEMPLARES CONSERVADOS EN LA BRITISH LIBRARY}

a) Madrid

Delicias de Apolo, recreaciones del Parnaso por las tres musas Vrania, Euterpe y Caliope: hechas de varias poesias de los mejores ingenios de España

Alegre, Melchor fl. 1665-1671 imp.

System number 018210988

[8], 174, [2], 175-177 [9]. El folio Y4r-Y4v sin paginar conserva su posición entre las pp. 174-175. Las cuatro hojas sin paginar restantes se incorporan al final de la antología, tras el "Soneto al Serenísimo don Juan de Austria”.

Carece de grabados.

Reproducido por Google Books: https://books.google.es/

books?vid=BL:A0021512331\&redir_esc=y [consultado el 2 de septiembre de 2017].

Delicias de Apolo, recreaciones del Parnaso por las tres musas Vrania, Euterpe y Caliope: hechas de varias poesias de los mejores ingenios de España

Alegre, Melchor fl. 1665-1671 imp.

System number 003657604

[8], 174, [10], 175-177, [1]. Las cinco hojas sin paginar se insertan entre las pp. 174-175

Carece de grabados.

b) Zaragoza

Delicias de Apolo, recreaciones del Parnaso por las tres musas Vrania, Euterpe y Caliope: hechas de varias poesias de los mejores ingenios de España

Ibar, Juan de imp.

[12], 177, [1]. Carece de las cinco hojas sin paginar.

System number 017931379

Carece de grabados.

Reproducido por la Biblioteca Británica:

http://access.bl.uk/item/viewer/ark:/81055/vdc_100033622437.0 
x000001\#ark:/81055/vdc_100033622550.0x0000c3 [consultado el 2 de septiembre de 2017].

Delicias de Apolo, recreaciones del Parnaso por las tres musas Vrania, Euterpe y Caliope: hechas de varias poesias de los mejores ingenios de España Ibar, Juan de imp.

[12], 177, [1]. Carece de las cinco hojas sin paginar.

System number 000049960

Carece de grabados.

Reproducido por Google Books: https://books.google.es/bo oks?id=Ai22nQEACAAJ\&pg=PA38\&hl=es\&source=gbs_ toc_r\&cad $=4 \# \mathrm{v}=$ onepage\&q\&f=false

[consultado el 2 de septiembre de 2017].

Como se puede apreciar, hay pequeñas variantes en la composición de los ejemplares, resultado de las varias ediciones y estados. La primera atańe a la inserción de cinco hojas sin paginar en las que se recogen textos que, con bastante probabilidad, llegaron a manos del editor una vez iniciado el proceso de impresión. Este cuaderno incluye además la anteportada del bloque dedicado a la musa Euterpe ${ }^{21}$, que Alfay no colocó al inicio del mismo. Su localización oscila según el ejemplar que consultemos, lo que es habitual en los casos de venta en rama. Por último, destaca el añadido eventual de grabados en algunos de los ejemplares. A continuación, trataremos de explicar cómo surgieron estos cambios durante la composición de la antología y su estrecha relación con la doble edición de este florilegio.

El cuerpo de las Delicias de Apolo al completo se gestó en un único taller tipográfico. La presencia de errores materiales comunes a las dos ediciones así lo confirma. Prueba de ello es la "u" invertida en la página 93 (Fig. 1):

\section{ventinrotor}

Fig. 1

21 Alfay acompañó cada musa de un frontispicio en el que, además de asentar la división de los bloques, expone la temática de cada uno de ellos. 
De este modo, las únicas diferencias entre los ejemplares —más allá de las hojas sin paginar-, se encuentran en los preliminares y en la portada, donde constan dos pies de imprenta distintos: el de Madrid y el de Zaragoza. Cabe, por tanto, preguntarse si nos encontramos ante una doble edición o ante una emisión, pues el cuerpo textual resulta idéntico ${ }^{22}$. No en vano, en numerosas descripciones bibliográficas de los ejemplares conservados de las Delicias se remite a una doble emisión. Nosotros, sin embargo, teniendo en cuenta que nos hallamos ante dos pies de imprenta distintos, preferimos hablar de dos ediciones.

Así las cosas, el florilegio comenzaría a gestarse en los talleres de Alfay con anterioridad a la muerte del VI duque de Alba el 7 de octubre de 1667, pues, como ya apuntamos, el zaragozano introduce en su edición una dedicatoria al noble y hasta prepara varios ejemplares con grabados en su honor, como explicaremos más adelante.

Probablemente, Alfay ya tenía impresos todos los poemas de la musa Urania y de la musa Euterpe cuando llegaron a sus manos algunas composiciones que insertó de forma irregular en cinco hojas sin paginar, así como en el bloque dedicado a la musa Calíope. Es posible que con motivo de esta nueva incorporación el zaragozano decidiera incluir entonces una anteportada al inicio de cada sección. El frontispicio de Euterpe se añadió a las antedichas cinco hojas; el de Calíope, al inicio del bloque correspondiente; mientras que en el caso de Urania la portada se insertó por error en el cuaderno perteneciente a los preliminares en la edición madrileña. La edición zaragozana, por el contrario, carece de la anteportada de Urania, a tenor de los ejemplares conservados ${ }^{23}$.

Es lícito conjeturar, por tanto, que las cinco hojas sin paginar debieran haberse ubicado al inicio del apartado relativo a Euterpe. Sin embargo, si

22 Ronald B. McKerrow, Introducción a la bibliografía material, trad. Isabel Moyano Andrés, Madrid, Arco Libros, 1998, p. 199.

23 En el caso de la edición madrileńa, encontramos un único cuaderno de preliminares; ocupa la portada la hoja 4. En la edición zaragozana, los ejemplares incluyen medio cuaderno más, pues insertan una segunda aprobación de José del Calvo Monreal y desaparece la portada de Urania. No obstante, sí se mantiene en el ejemplar R/3056 de la BNE, dedicado al duque de Alba, el cual posee algunas características especiales, como la incorporación de grabados y la supresión de la aprobación de José del Calvo. Se trata, por tanto, de un ejemplar híbrido que, como veremos más adelante, se cuidó especialmente. 
analizamos todos los ejemplares conservados y atendemos a la formación de sus pliegos, descubrimos que la primera de estas cinco hojas pertenece al cuaderno Y de la antología. Es decir, la hoja en la que se incluye la anteportada de Euterpe se corresponde con el folio Y4, que forzosamente debería disponerse tras la página 174, es decir, el Y3v. Las cuatro hojas restantes forman un cuaderno independiente que, por lógica, debiera colocarse tras Y4.

De este modo, podemos afirmar que la disposición de estos cinco folios entre las páginas 174 y 175 no es accidental, sino que obedece al diseño editorial de la antología, que quedó supeditado al orden de recepción de los textos. La disposición, empero, es un tanto antojadiza, pues supone la inserción de tres poemas pertenecientes a la musa Euterpe en el bloque dedicado a Calíope. Muchos lectores debieron darse cuenta de ello, por lo que se conservan ejemplares reencuadernados en los que estas cinco hojas se postergan al final de la antología, tras el "Soneto al serenísimo don Juan de Austria”, o bien se adelantan, insertándose después de los preliminares, como ocurre en el ejemplar XVII/1072 de la Biblioteca Valenciana Nicolau Primitiu. Asimismo, también es llamativa la distribución de estas cinco hojas en el ejemplar 018210988 de la Biblioteca Británica, donde se mantiene Y4 entre las páginas 174-175 (Fig. 2), mientras que las cuatro hojas restantes pasan al final del florilegio (Fig. 3). Todas estas vacilaciones evidencian que se trataba de un diseño bastante peculiar incluso en su época.

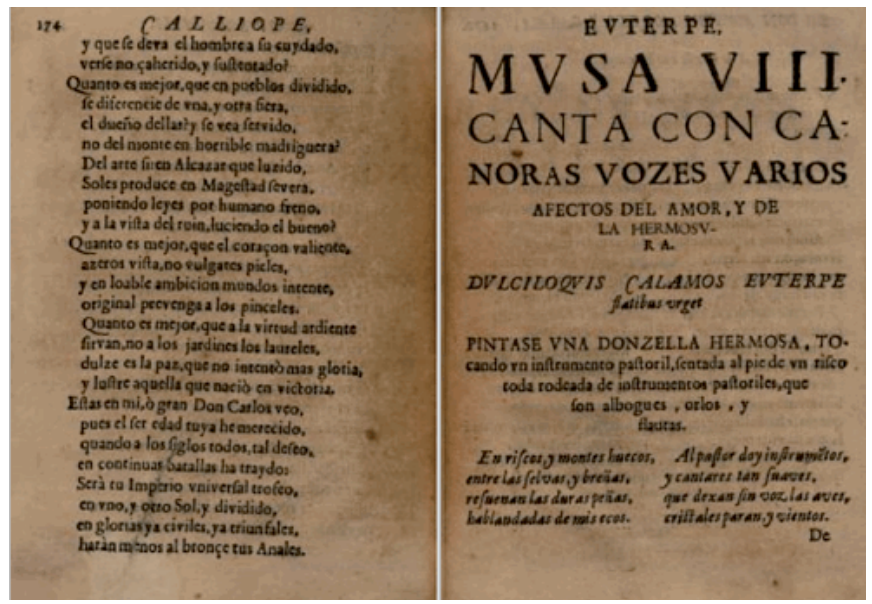

Fig. 2 


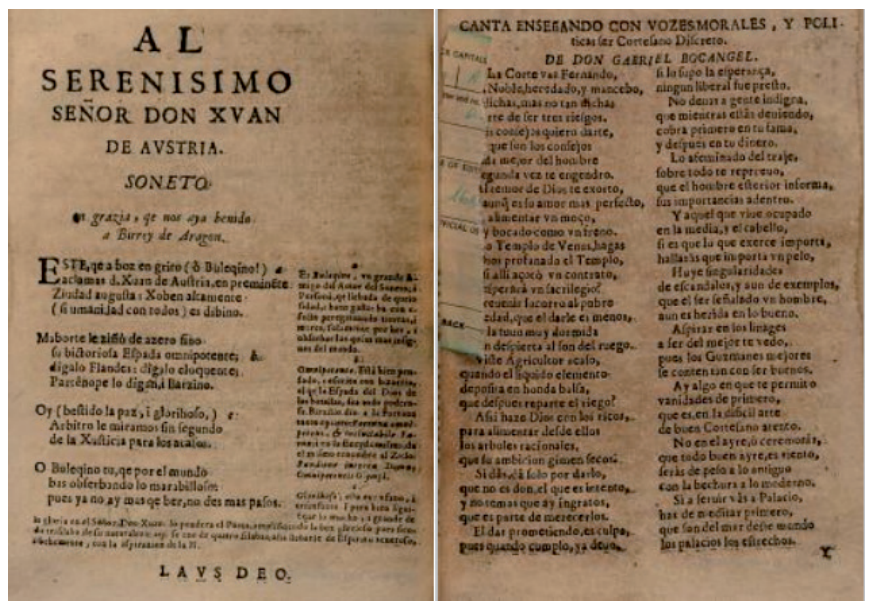

Fig. 3

Cabe pensar que Alfay vendiera el florilegio en rama a su amigo Francisco de la Torre - quien podría haber costeado parte de la empresa—, y que este enviara a su vez el florilegio al Consejo de Castilla, aún sin terminar. De ahí que la aprobación de la edición madrileña venga fechada el 8 de marzo de 1669 y la de la zaragozana date del 10 de junio de 1670. Ello no implica, empero, que la primera sea anterior, pues, como dijimos, la dedicatoria al duque de Alba debe ser previa a 1667. Una vez sorteados los obstáculos legales, Francisco de la Torre imprimiría los preliminares pertenecientes a la edición madrileńa en la minerva de Melchor Alegre, reivindicando en su "Prólogo al lector" la paternidad de la obra; mientras que Alfay lo haría en el taller de Juan Ibar. El uso de diferentes tipos tan solo en este cuaderno avalaría nuestra hipótesis (Figs. 4 y 5).

\section{PROLOGO AL LE'TOR.}

Fig. 4. Edición madrileña

\section{Prologo al Lector.}

Fig. 5. Edición zaragozana

A propósito de los preliminares, destaca que la edición zaragozana consta de medio pliego más, en el que se incluye la aprobación de José de Calvo y Montreal. A pesar de que se trata de un paratexto propio de la tirada aragonesa, el ejemplar 8/30886 de la BNE, perteneciente a la edición madrileña, también lo incorporó. Se trata, evidentemente, de un ejemplar reencuader- 
nado en pergamino que se compuso a partir de dos ejemplares distintos.

En cuanto a la paternidad de la obra, Alfay reclama la autoría del libro en la dedicatoria al IV señor de la casa de Alba, don Fernando Álvarez de Toledo: "cierto estoy de que este breve volumen que pongo a los pies de vuestra señoría con su sombra y protección quedará libre de la más mordaz envidia [...]; conque a un mismo tiempo quedará este ennoblecido, y yo acreditado en la elección de poemas" ${ }^{24}$. El paratexto explicaría también por qué algunos ejemplares lucen una encuadernación distinta e incluyen grabados. Si Alfay pensaba dedicar su antología a este prócer — seguramente con el propósito de obtener algún beneficio económico-, sería lógico que también le ofreciera algunos ejemplares —entre ellos, el llamativo volumen $\mathrm{R} / 3056$, en el que, amén de la incorporación de calcografías, destaca la supresión de la aprobación de Calvo y la incorporación de la anteportada de Urania-, los cuales gozaron de especial atención por parte del encuadernador. La muerte del aristócrata en 1667 frustró los planes del librero. No obstante, es posible que el zaragozano remitiera los volúmenes a su hijo, Antonio Álvarez de Toledo, VII duque de Alba, y que por ello no eliminase ni la dedicatoria ni el grabado de su escudo de armas (Fig. 6). Como es habitual, algunos ejemplares han perdido varias de estas xilografías.

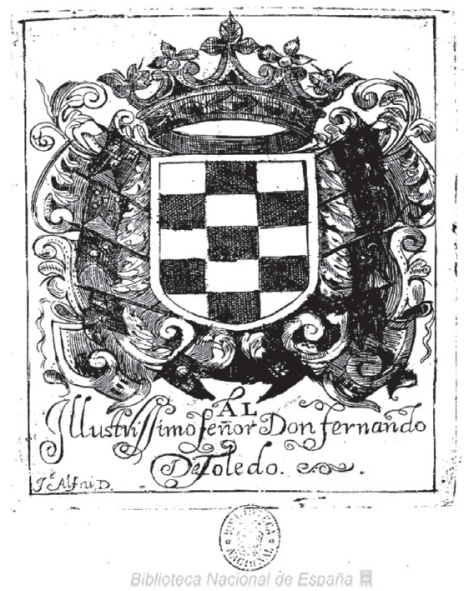

Fig. 6. Ejemplar R/3056, BNE.

24 José Alfay (ed.), Delicias de Apolo, recreaciones del Parnaso, por las tres musas Urania, Euterpe y Caliope. Hechas de varias poesías de los Mejores ingenios de España, Zaragoza, Juan Ibar, 1670, fol. 93. 


\section{Las Delicias de Apolo y las Poesías Varias: textos reciclados / TEXTOS INCORPORADOS}

Por lo que se refiere a la disposición textual, no es fácil discernir hasta qué punto Gracián colaboró en la formación y dispositio de las Poesías varias, a las que tanto deben las Delicias de Apolo, si bien parece obligado hacer algunas consideraciones al respecto. En las Poesías varias se recopilan un total de 131 poemas calificados por el propio Alfay como “ingeniosos"25. Góngora, Quevedo, Lope y Calderón comparten protagonismo aquí con un sinnúmero de vates del Bajo Barroco ${ }^{26}$, más o

25 El ingenio se relacionaba en la época directamente con el conceptismo, "acto de entendimiento que exprime la correspondencia que se halla entre los objetos", como señala Baltasar Gracián, Agudeza y arte de ingenio, ed. E. Correa Calderón, Madrid, Castalia, 1969, p. 55; quien prosigue: "esta conformidad o simpatía entre los conceptos y el ingenio en alguna perfección se funda, en algún sutilísimo artificio, que es la causa radical de que se conforme la agudeza". Véase ibidem, p. 53. Amén de su relación directa con el concepto, el ingenio se relaciona con la velocidad, pues "luce más [...] al ser puesto a prueba y tener que contestar de inmediato a un ataque o estímulo verbal externo". Véase Rodrigo Cacho Casal, La esfera del ingenio. Las silvas de Quevedo y la tradición europea, Madrid, Grupo Editorial Siglo XXI, 2012, p. 25. Asimismo, según Mercedes Blanco, "Noms de l'Intelligence: entendimiento, discreción, ingenio, juicio", en Les Rhétoriques de la Pointe. Baltasar Gracián et le Conceptisme en Europe, Genève, Editions Slatkine, 1992, pp. 30-33 (p. 31), "quant à ingenio, son étymologie, qui le relie aux mots de la famille de gingnere, lui reste attachée dans la consciencie linguistique. Il connote en effect le caractère inné de dons intellectuels, et, surtout il a vocation de désigner cet aspect de l'intelligence qui la rend propre à «engendrer», à inventer, à produire du noveau. Calderón interprète cette étymologie en reliant l'ingenio à «ingénéré», non engendré, Ingenitus. Mot du vocabulaire théologique que s'applique à la première personne de la Trinité, au Père, créateur du monde et géniteur du Verbe, que l'on apelle Unigenitus, l'unique engendré. Le mot ingenio, «syncope» de ingénito, designe un pouvoir générateur et créateur, propre à ce qui est «non engendré», pouvoir qui est «syncope» du celui de l'Etre infini".

26 Según Pedro Ruiz Pérez, "Para la historia y la crítica de un periodo oscuro: la poesía del Bajo Barroco", Calíope, XVIII, 1 (2012), pp. 9-25 (p. 25), el Bajo Barroco se identifica con "el discurso lírico tejido entre la muerte de Quevedo o la aparición de su Parnaso Español y la defunción de Eugenio Gerardo Lobo, a las puertas de la poesía ilustrada". Se trata de un periodo que oscila, pues, entre 1650 y 1750 


\section{menos afortunados (Francisco de la Torre, Bocángel, Diego de Frías, Villaizán, etc.).}

\begin{tabular}{|c|c|c|c|c|}
\hline \multicolumn{5}{|c|}{ Poesias varias de grandes ingenios españoles (Zaragoza, 1654) } \\
\hline No & Título & Primer verso & Autor & Métrica \\
\hline I & $\begin{array}{l}\text { A una dama disuádele no se } \\
\text { case. Soneto. }\end{array}$ & "Desdicha, hermosura y novia" & $\begin{array}{l}\text { Antonio Hurtado de Men- } \\
\text { doza (1586-1644) }\end{array}$ & Romance \\
\hline II & $\begin{array}{l}\text { Al túmulo del Rey que se hizo } \\
\text { en Sevilla. }\end{array}$ & $\begin{array}{l}\text { "Voto a Dios que me espanta esta } \\
\text { grandeza" }\end{array}$ & $\begin{array}{l}\text { Miguel de Cervantes (1547- } \\
1617 \text { ) }\end{array}$ & Soneto \\
\hline IIII & Al mosquito de trompetilla. & "Saturno, alado ruïdo" & $\begin{array}{l}\text { Francisco de Quevedo } \\
(1580-1645)\end{array}$ & Décima \\
\hline IV & $\begin{array}{l}\text { Romance de los toros de } \\
\text { Madrid. }\end{array}$ & "Oye, Marica, que vengo" & $\begin{array}{l}\text { [Gabriel Bocángel (1603- } \\
1658)]\end{array}$ & Romance \\
\hline V & $\begin{array}{l}\text { A uno que por ausentarse } \\
\text { en el servicio se asentó en el } \\
\text { brasero. }\end{array}$ & "En Fuenmayor, esa villa" & & Romance \\
\hline VI & $\begin{array}{l}\text { Al Padre Pineda porque no le } \\
\text { dio precio en un certamen. }\end{array}$ & $\begin{array}{l}\text { "EE justa injusta expuesto a la } \\
\text { sentencia” }\end{array}$ & $\begin{array}{l}\text { Luis de Góngora (1561- } \\
1627)\end{array}$ & Romance \\
\hline VII & Respuesta del Padre Pineda. & $\begin{array}{l}\text { "En la justa muy justa la sen- } \\
\text { tencia" }\end{array}$ & Padre Pineda (1558-1637) & Soneto \\
\hline VIII & Décima. & "Refieren muy resolutos" & $\begin{array}{l}\text { Francisco de la Torre y Sevil } \\
(1625-1681)\end{array}$ & Décima \\
\hline IX & $\begin{array}{l}\text { Romance gustoso. Consejos } \\
\text { que da una vieja a una niña. }\end{array}$ & "Una cortesana vieja" & $\begin{array}{l}\text { [Alonso de Ledesma (1562- } \\
1623)]\end{array}$ & Romance \\
\hline $\mathrm{X}$ & A don Francisco de Quevedo. & $\begin{array}{l}\text { "Anacreonte español, no hay } \\
\text { quien os tope" }\end{array}$ & $\begin{array}{l}\text { Luis de Góngora (1561- } \\
1627)\end{array}$ & Soneto \\
\hline $\mathrm{XI}$ & $\begin{array}{l}\text { A una mujer que, siendo } \\
\text { muy puerca, presumía que la } \\
\text { querian por hermosa. }\end{array}$ & "Sin esperar la lucha picaril" & $\begin{array}{l}\text { [Luis de Góngora (1561- } \\
1627)]\end{array}$ & Soneto \\
\hline XII & Al ruiseñor. & "Flor con flor, radiante flor" & $\begin{array}{l}\text { Francisco de Quevedo } \\
(1580-1645)\end{array}$ & Décima \\
\hline XIII & $\begin{array}{l}\text { A la fiesta de toros real que a } \\
\text { los felicísimos años de la Rei- } \\
\text { na Nuestra Señora se celebró } \\
\text { en Madrid. }\end{array}$ & "Gran héroe, duque de Sessa" & $\begin{array}{l}\text { Gabriel Bocángel (1603- } \\
1658)\end{array}$ & Romance \\
\hline XIV & A Lope de Vega. & $\begin{array}{l}\text { "Por tu vida, Lopillo, que me } \\
\text { borres" }\end{array}$ & $\begin{array}{l}\text { Luis de Góngora (1561- } \\
1627)\end{array}$ & Soneto \\
\hline $\mathrm{XV}$ & Romance lírico. A unos ojos. & "Los más bellos ojos negros" & $\begin{array}{l}\text { Antonio Hurtado de Men- } \\
\text { doza }(1586-1644)\end{array}$ & Romance \\
\hline XVI & Al regüeldo. & "El regüeldo, bien mirado" & & Quintilla \\
\hline XVII & Romance lírico. & "La preñadilla de Antón" & & Romance \\
\hline XVIII & Soneto. & $\begin{array}{l}\text { "¿Para qué, dime Marcia, te } \\
\text { perfumas" }\end{array}$ & $\begin{array}{l}\text { Luis de Góngora }(1561- \\
1627)\end{array}$ & Soneto \\
\hline XIX & A unos celos. & "En las orillas del Tajo" & $\begin{array}{l}\text { Luis de Góngora (1561- } \\
1627 \text { ) }\end{array}$ & Romance \\
\hline $\mathrm{XX}$ & A un presente de aceitunas. & "Para hacerles el proceso" & & Décima \\
\hline XXI & Romance. A una caza. & "Saca el Oriente a la Aurora" & García de Porras ?? & \\
\hline XXII & A don Francisco de Quevedo. & "Si no sabéis, señora de Cetina" & & Soneto \\
\hline
\end{tabular}

aproximadamente, "situado entre lo que se consideran dos haces de luz, la Edad de Oro y la Ilustración” (Ibidem, p. 10). 


\begin{tabular}{|c|c|c|c|c|}
\hline XXIII & $\begin{array}{l}\text { Al suceso de don Francisco de } \\
\text { Quevedo con una fea. }\end{array}$ & "Empujar quiero mi voz" & & Romance \\
\hline XXIV & A la fuente de Garcilaso. & "Pasajero, a la gran fuente" & $\begin{array}{l}\text { [Bartolomé Juan Leonardo } \\
\text { de Argensola (1562-1631)] }\end{array}$ & Décima \\
\hline$X X Y$ & Sátira. & "Cuando volví de las Indias" & $\begin{array}{l}\text { Luis de Góngora (1561- } \\
1627)\end{array}$ & Romance \\
\hline XXVI & A un valiente. & $\begin{array}{l}\text { "Un valentón de espátula y gre- } \\
\text { güesco" }\end{array}$ & $\begin{array}{l}\text { Miguel de Cervantes (1547- } \\
\text { 1617)] }\end{array}$ & Soneto \\
\hline XXVII & A una boca. & "Clavel dividido en dos" & $\begin{array}{l}\text { Juan Pérez de Montalbán } \\
(1602-1638)\end{array}$ & Romance \\
\hline XXVIII & A la fuente de Garcilaso. & "Este sonoro cristal" & $\begin{array}{l}\text { Francisco de Sayas (princi- } \\
\text { pios XVII-1680) }\end{array}$ & Décima \\
\hline XXIX & Fábula de Atalanta. & "Esquiva Atalanta siempre" & $\begin{array}{l}\text { Valentín de Céspedes (1595- } \\
1668)\end{array}$ & Romance \\
\hline $\mathrm{XXX}$ & Contra los cultos. & $\begin{array}{l}\text { "-Boscán, tarde llegamos. -¿Hay } \\
\text { posada?” }\end{array}$ & $\begin{array}{l}\text { Lope de Vega y Carpio } \\
(1562-1635)\end{array}$ & Soneto \\
\hline XXXI & Romance. & "El alba, Marica" & $\begin{array}{l}\text { Antonio Hurtado de Men- } \\
\text { doza (1586-1644) }\end{array}$ & Romance \\
\hline XXXII & Redondilla. & "El galán que me quisiere" & $\begin{array}{l}\text { Juan de Horozco y Covarru- } \\
\text { bias }(1540-1610)\end{array}$ & $\begin{array}{l}\text { Redon- } \\
\text { dilla }\end{array}$ \\
\hline XXXIII & $\begin{array}{l}\text { Romance amoroso. Retrata } \\
\text { una hermosura. }\end{array}$ & "La flota que de Indias vino" & $\begin{array}{l}\text { Atribuido a Luis de Góngora } \\
(1561-1627)\end{array}$ & Romance \\
\hline XXXIV & Epitafio. & "-En esta piedra yace un mal & $\begin{array}{l}\text { Francisco de Quevedo } \\
(1580-1645)\end{array}$ & $\begin{array}{l}11 \mathrm{~A} 7 \mathrm{a} \\
11 \mathrm{~B} 7 \mathrm{~b}\end{array}$ \\
\hline XXXVI & A un luto. & "La beldad más peregrina" & Diego Morlanés ¿? & Romance \\
\hline XXXVII & A un rio helado. & "Salid, joh, Clori divina!" & García de Porras ¿? & Romance \\
\hline XXXVIII & Al mosquito del vino. & "Mota, borracha, golosa" & $\begin{array}{l}\text { Francisco de Quevedo } \\
(1580-1645)\end{array}$ & Décima \\
\hline XXXIX & De un borracho a una bota. & "A una bota de Peralta" & & $\begin{array}{l}\text { Copla de } \\
\text { pie que- } \\
\text { brado }\end{array}$ \\
\hline $\mathrm{XL}$ & Vejamen a Judas. & "A Judas vejamen doy" & & Coplas \\
\hline XLI & A una rosa. & "Estas exhalaciones peregrinas" & $\begin{array}{l}\text { Francisco de Sayas (princi- } \\
\text { pios XVII-1680) }\end{array}$ & Soneto \\
\hline XLII & $\begin{array}{l}\text { Romance amoroso. A una } \\
\text { dama. }\end{array}$ & "¿No me conocéis, serranos?" & García de Porras ? & Romance \\
\hline XLIII & $\begin{array}{l}\text { Refiere las quejas de un } \\
\text { verdugo. Letrilla satírica. }\end{array}$ & "Un verdugo se quejaba" & $\begin{array}{l}\text { Diego Hurtado de Mendoza } \\
(1503 / 4-1575)\end{array}$ & Romance \\
\hline XLIV & $\begin{array}{l}\text { Redondilla al romance de } \\
\text { Piramo y Tisbe de don Luis } \\
\text { de Góngora. }\end{array}$ & "Este romanzón compuso" & & $\begin{array}{l}\text { Redon- } \\
\text { dilla }\end{array}$ \\
\hline XLV & Romance satírico. & "Escuchadme atentamente" & & Romance \\
\hline XLVI & A la Magdalena. & $\begin{array}{l}\text { "Difunta al gusto, viva ya a la } \\
\text { pena" }\end{array}$ & $\begin{array}{l}\text { Francisco de la Torre y Sevil } \\
(1625-1681)\end{array}$ & Soneto \\
\hline XLVII & A una dama. & "La bella deidad del Tajo" & $\begin{array}{l}\text { Luis de Góngora (1561- } \\
1627)\end{array}$ & Romance \\
\hline XLVIII & $\begin{array}{l}\text { Epitafio. A un hombre } \\
\text { pequeño. }\end{array}$ & "Caminante, aguarda, espera" & & $\begin{array}{l}\text { Copla } \\
\text { novena }\end{array}$ \\
\hline XLIX & Romance. & "Hijo mío, no te engañe" & $\begin{array}{l}\text { Luis de Góngora (1561- } \\
\text { 1627) }\end{array}$ & Romance \\
\hline $\mathrm{L}$ & Quintilla. & "Aquí se vende, lector" & & Quintilla \\
\hline LI & Romance. & "Justicia en dos puntos hecha" & $\begin{array}{l}\text { Luis de Góngora (1561- } \\
1627 \text { ) }\end{array}$ & Romance \\
\hline LII & $\begin{array}{l}\text { A un poeta concorvado que } \\
\text { se valió de trabajos ajenos de } \\
\text { varios ingenios. }\end{array}$ & "De las ya fiestas reales" & $\begin{array}{l}\text { Luis de Góngora (1561- } \\
\text { 1627) et alii. }\end{array}$ & Décima \\
\hline
\end{tabular}




\begin{tabular}{|c|c|c|c|c|}
\hline LIII & Fábula de Apolo y Dafne. & "Aquel dios, ciego y malsín" & $\begin{array}{l}\text { Alonso Jerónimo Salas de } \\
\text { Barbadillo (1581-1635) }\end{array}$ & Romance \\
\hline LIV & $\begin{array}{l}\text { Epitafio. A una descansada } \\
\text { que murió de cámaras. }\end{array}$ & "Aquí yace Mari Blas" & & $\begin{array}{l}\text { Redon- } \\
\text { dilla }\end{array}$ \\
\hline LV & Endechas líricas. & "Pastores, ;que me abraso!" & $\begin{array}{l}\text { Antonio Hurtado de Men- } \\
\text { doza (1586-1644) }\end{array}$ & Endecha \\
\hline LVI & A una voz de una dama. & "La mano en el instrumento" & & Décima \\
\hline LVII & Endechas. & "Jueves, era jueves" & $\begin{array}{l}\text { Luis de Góngora (1561- } \\
\text { 1627) }\end{array}$ & Endechas \\
\hline LVIII & Redondilla burlesca. & "Señora, no puedo más" & & $\begin{array}{l}\text { Redon- } \\
\text { dilla }\end{array}$ \\
\hline LIX & Fábula de Adonis. & " $\mathrm{Oh}$, dulce amor de mi pluma" & Don Diego de Frías ¿? & Romance \\
\hline $\mathrm{LX}$ & $\begin{array}{l}\text { A un clavel en la boca de una } \\
\text { dama. }\end{array}$ & $\begin{array}{l}\text { "Un clavel, de Lucinda enamo- } \\
\text { rado" }\end{array}$ & Gaspar de Sotelo ¿? & Soneto \\
\hline LXI & Romance amoroso. & "En la mudanza de Hila" & $\begin{array}{l}\text { Antonio Hurtado de Men- } \\
\text { doza }(1586-1644)\end{array}$ & Romance \\
\hline LXII & A un desmayo. & "Flor con alma, la más fiel" & Gaspar de Sotelo ¿? & Décima \\
\hline LXIII & A un pensamiento. & "Atrevidos pensamientos" & $\begin{array}{l}\text { Jerónimo de Villayzán } \\
(1604-1633)\end{array}$ & Romance \\
\hline LXIV & A la rosa. & "Rompe la concha de esmeraldas & $\begin{array}{l}\text { Francisco de la Torre y Sevil } \\
(1625-1681)\end{array}$ & Soneto \\
\hline LXV & A unos ojos. & "Más que el basilisco, Inés" & $\begin{array}{l}\text { Francisco de Quevedo } \\
(1580-1645)\end{array}$ & $\begin{array}{l}\text { Redondi- } \\
\text { llas }\end{array}$ \\
\hline LXVI & A unos ojos negros. & "Ojos, de cuyo esplendor" & $\begin{array}{l}\text { Jerónimo de Cáncer y Velas- } \\
\text { co (:1599?-1655) }\end{array}$ & Décimas \\
\hline LXVII & A una partida. & "Quedad sobre ese peñasco" & Luis de Góngora (1561- & Romance \\
\hline LXVIII & $\begin{array}{l}\text { Una dama al Duque de } \\
\text { Lerma al subir en la carroza } \\
\text { real que hizo de repente un } \\
\text { estudiante para que se lo } \\
\text { diese. }\end{array}$ & "Doña Juana de Bolanes" & & $\begin{array}{l}\text { Redondi- } \\
\text { llas }\end{array}$ \\
\hline LXIX & A un tuerto. & "El yerro tengo por cierto" & $\begin{array}{l}\text { Antonio Hurtado de Men- } \\
\text { doza (1586-1644) }\end{array}$ & $\begin{array}{l}\text { Redondi- } \\
\text { llas }\end{array}$ \\
\hline LXX & Romance lírico. & "Compitiendo con las selvas" & $\begin{array}{l}\text { Antonio Hurtado de Men- } \\
\text { doza }(1586-1644)\end{array}$ & Romance \\
\hline LXXI & Quintilla. & "Tanta de córcova atrás" & Regidor Juan Fernández ¿? & Quintilla \\
\hline LXXII & Dido y Eneas. & "El fugitivo troyano" & $\begin{array}{l}\text { Alonso Jerónimo Salas de } \\
\text { Barbadillo (1581-1635) }\end{array}$ & Romance \\
\hline LXXIII : & A un olmo caída la hoja. & $\begin{array}{l}\text { "Olmo fui ayer, ;oh, hipérbole } \\
\text { florido!" }\end{array}$ & $\begin{array}{l}\text { Antonio Hurtado de Men- } \\
\text { doza }(1586-1644)\end{array}$ & Soneto \\
\hline LXXIV & Endechas. & "Junto a una fuente clara" & $\begin{array}{l}\text { Luis de Góngora (1561- } \\
1627)\end{array}$ & Endechas \\
\hline LXXV & Al jardín de Lisis. & "Si miras la amenidad" & García de Porras ¿? & Décimas \\
\hline LXXVI & Sátira. & "Atención por vida mía" & $\begin{array}{l}\text { Luis de Góngora (1561- } \\
1627 \text { ) }\end{array}$ & Romance \\
\hline LXXVII & A las obras de Lope de Vega. & $\begin{array}{l}\text { "Aquí del Conde Claros, dijo, y } \\
\text { luego" }\end{array}$ & $\begin{array}{l}\text { Luis de Góngora (1561- } \\
1627)\end{array}$ & Soneto \\
\hline LXXVIII & $\begin{array}{l}\text { Probando ser mejor desgracia- } \\
\text { do discreto que necio virtuoso }\end{array}$ & "Si el necio, aunque afortunado" & $\begin{array}{l}\text { Antonio Hurtado de Men- } \\
\text { doza }(1586-1644)\end{array}$ & Décima \\
\hline LXXIX & Prueba lo contrario. & "Una perpetua esperanza" & $\begin{array}{l}\text { Antonio Hurtado de Men- } \\
\text { doza (1586-1644) }\end{array}$ & Décima \\
\hline LXXX & Prueba contra lo uno y lo & "El que no llega a saber" & $\begin{array}{l}\text { Antonio Hurtado de Men- } \\
\text { doza }(1586-1644)\end{array}$ & Décima \\
\hline LXXXI & A una nariz grande. & "Tu nariz, hermana Clara" & $\begin{array}{l}\text { Baltasar de Alcázar (1530- } \\
1603)\end{array}$ & $\begin{array}{l}\text { Redondi- } \\
\text { llas }\end{array}$ \\
\hline
\end{tabular}




\begin{tabular}{|c|c|c|c|c|}
\hline LXXXII & A un cuidado. & "Rabioso y mortal cuidado" & $\begin{array}{l}\text { Luis de Góngora (1561- } \\
1627 \text { ) }\end{array}$ & Romance \\
\hline LXXXIII & A un hombre flaco. & "Dígasme, tú, el esqueleto" & $\begin{array}{l}\text { Luis Vélez de Guevara } \\
(1579-1644)\end{array}$ & Romance \\
\hline LXXXIV & Letrilla amorosa. & "Paloma era mi querida" & $\begin{array}{l}\text { Luis de Góngora (1561- } \\
1627 \text { ) }\end{array}$ & $\begin{array}{l}\text { Romance } \\
\text { con estri- } \\
\text { billo }\end{array}$ \\
\hline LXXXV & Romance amoroso. & "La gala de la hermosura" & $\begin{array}{l}\text { Antonio Hurtado de Men- } \\
\text { doza (1586-1644) }\end{array}$ & Romance \\
\hline LXXXVI & Enigma. & "Deme el discreto razón" & $\begin{array}{l}\text { Francisco de la Torre y Sevil } \\
(1625-1681)\end{array}$ & $\begin{array}{l}\text { Quinti- } \\
\text { llas }\end{array}$ \\
\hline $\begin{array}{l}\text { LXXX- } \\
\text { VII }\end{array}$ & A Policena. & "Enternecido el sepulcro" & $\begin{array}{l}\text { Luis de Góngora (1561- } \\
1627 \text { ) }\end{array}$ & Romance \\
\hline $\begin{array}{l}\text { LXXX- } \\
\text { VIII }\end{array}$ & $\begin{array}{l}\text { Cuenta la vida desastrada de } \\
\text { un hombre. }\end{array}$ & "El pintor de cuchilladas" & & Soneto \\
\hline LXXXIX & Fábula de Jupiter y Europa. & "Nació Europa, ninfa bella" & José Zaporta ¿? & Décimas \\
\hline $\mathrm{XC}$ & Jácara. & "Parado estaba a una esquina" & & Romance \\
\hline XCI & Jácara. & "Inesilla de Segovia" & & Romance \\
\hline XCII & $\begin{array}{l}\text { A mi señora doña Ana } \\
\text { Chaflón, tundidora de gustos, } \\
\text { que de puro añeja se pasa de } \\
\text { noche como cuarto falso. }\end{array}$ & "Con enaguas la Tusona" & $\begin{array}{l}\text { Francisco de Quevedo } \\
(1580-1645)\end{array}$ & Romance \\
\hline XCIII & Jácara. & "Con el mulato de Andújar" & Pedro Panzano ?? & Romance \\
\hline XCIV & Jácara nueva burlesca. & "Aquel racional mosquito" & & Romance \\
\hline $\mathrm{XCV}$ & A las medias de pelo. & "Oigan, señores galanes" & & Romance \\
\hline XCVI & $\begin{array}{l}\text { A una dama que se corres- } \\
\text { pondia con un capón. }\end{array}$ & "Dicen que tienes, Juanilla" & & Romance \\
\hline XCVII & [Sin titulo] & "En la trapería" & & \\
\hline XCVIII & La mariposa. & "En la más noble región" & & Romance \\
\hline XCIX & Pintura a una dama. & "Oye, Amarilis discreta" & $\begin{array}{l}\text { Jerónimo de Cáncer y Velas- } \\
\text { co }(\$ 1599 ?-1655)\end{array}$ & $\begin{array}{l}\text { Pie que- } \\
\text { brado }\end{array}$ \\
\hline $\mathrm{C}$ & $\begin{array}{l}\text { A un álamo injuriado por } \\
\text { el viento. }\end{array}$ & "Álamo, águila hojosa que volaste" & [Pedro de Castro 1610-¿?] & Soneto \\
\hline $\mathrm{CI}$ & $\begin{array}{l}\text { Danida a Cloris en su au- } \\
\text { sencia. }\end{array}$ & "Deidad desta ribera" & & Silva \\
\hline CII & [Sin titulo] & "Con los ojos de Gileta" & & Romance \\
\hline CIII & [Sin titulo] & "Si de los ojos hermosos" & & $\begin{array}{l}\text { Roman- } \\
c^{*}\end{array}$ \\
\hline CIV & $\begin{array}{l}\text { Letrilla que se cantó en Ma- } \\
\text { drid a una dama de Palacio. }\end{array}$ & "Porque está llorando el alba” & & Romance \\
\hline CV & Romance. & "Famoso Guadalquivir" & $\begin{array}{l}{[\text { Lope de Vega y Carpio }} \\
(1562-1635)]\end{array}$ & Romance \\
\hline CVI & A ciertos murmuradores. & "Mandasme, amigo carísimo" & & $\begin{array}{l}\text { Cuartetas } \\
\text { esdrúju- } \\
\text { las. }\end{array}$ \\
\hline CVII & $\begin{array}{l}\text { A un hombre calvo natural } \\
\text { de Velilla que compuso un } \\
\text { tratado de su campana. }\end{array}$ & "Un discurso campanil" & & $\begin{array}{l}\text { Redondi- } \\
\text { llas }\end{array}$ \\
\hline CVIII & Letra. & "A pesar del Prado sale" & & Romance \\
\hline CIX & Fábula de Mirra. & "Canto de Amor los horrores" & $\begin{array}{l}\text { Valentín de Céspedes (1595- } \\
1668)\end{array}$ & Romance \\
\hline
\end{tabular}




\begin{tabular}{|c|c|c|c|c|}
\hline CX & $\begin{array}{l}\text { Entretenimiento jocoso con } \\
\text { que se riñe la hermosura de } \\
\text { una dama. }\end{array}$ & $\begin{array}{l}\text { "Hermosísima Julia, que a pe- } \\
\text { llizcos" }\end{array}$ & & Pareados \\
\hline CXI & $\begin{array}{l}\text { A una dama que salía a } \\
\text { tomar el acero, viéndola su } \\
\text { amante recobrado el color. }\end{array}$ & "Camina en tu breve esfera" & [Antonio Cuello ¿?] & Décimas \\
\hline CXII & $\begin{array}{l}\text { Hizo conjetura un amante } \\
\text { por el tamaño de la mano } \\
\text { de su dama que sería breve } \\
\text { el pie. }\end{array}$ & "De tanta nieve viviente" & & Décima \\
\hline CXIII & $\begin{array}{l}\text { Yendo a una recreación unos } \\
\text { amigos, hace la suma del } \\
\text { regalo que les hizo. }\end{array}$ & "Insignísimos amigos" & & Romance \\
\hline CXIV & A un sueño. & "Con recia confianza" & & Liras \\
\hline CXV & [Sin titulo] & "Oye, amigo; oye, cochero" & Alberto Díez y Foncalda ¿? & \\
\hline CXVI & $\begin{array}{l}\text { Declarando si son los guar- } \\
\text { dadamas los tres enemigos del } \\
\text { alma, o si son otro enemigo } \\
\text { diferente. }\end{array}$ & "Amigos guardadamas" & Antonio Cohelo ¿? & Endechas \\
\hline CXVII & $\begin{array}{l}\text { Quejose Añasco de sus desdi- } \\
\text { chas y encarga la virtud a los } \\
\text { hombres. }\end{array}$ & "A la Chillona se queja" & & Romance \\
\hline CXVIII & $\begin{array}{l}\text { A una dama muy interesada } \\
\text { habiéndola visto tropezar. }\end{array}$ & "Cayó Inés, y yo no niego" & $\begin{array}{l}\text { Francisco de la Torre y Sevil } \\
(1625-1681)\end{array}$ & \\
\hline CXIX & $\begin{array}{l}\text { Que por qué llaman a las feas } \\
\text { entendidas si es la fealdad la } \\
\text { mayor necedad. }\end{array}$ & "Yo digo que las feas" & $\begin{array}{l}\text { Antonio de Solís y Rivade- } \\
\text { neyra (1610-1686) }\end{array}$ & $\begin{array}{l}\text { Seguidi- } \\
\text { llas }\end{array}$ \\
\hline CXX & $\begin{array}{l}\text { A una boca grande de una } \\
\text { mujer. }\end{array}$ & "Al ver tu hocico extendido" & $\begin{array}{l}\text { Francisco de la Torre y Sevil } \\
(1625-1681)\end{array}$ & $\begin{array}{l}\text { Redondi- } \\
\text { llas }\end{array}$ \\
\hline CXXI & A la fortuna. & "Juráralo, yo, Fortuna” & $\begin{array}{l}\text { Anastasio Pantaleón de } \\
\text { Ribera }(1600-1629)\end{array}$ & Romance \\
\hline CXXII & El retrato de otra Julia. & "Allá va de mi cielo" & & $\begin{array}{l}\text { Seguidi- } \\
\text { llas }\end{array}$ \\
\hline CXXIII & $\begin{array}{l}\text { Que haya sido misterio de } \\
\text { entorpecerse de Saú, cuando } \\
\text { tocaba el arpa David. }\end{array}$ & $\begin{array}{l}\text { "En el arpa, en los dedos o en el } \\
\text { viento" }\end{array}$ & & Soneto \\
\hline CXXIV & $\begin{array}{l}\text { Al estrago de la predicación } \\
\text { evangélica. }\end{array}$ & $\begin{array}{l}\text { "Pregúntasme por qué con tanto } \\
\text { ahínco" }\end{array}$ & [De un grande ingenio] & Cuartetos \\
\hline CXXV & $\begin{array}{l}\text { A una dama fea y negra que } \\
\text { se pintaba. }\end{array}$ & "Con polvos Lisis se pinta" & $\begin{array}{l}\text { Francisco de la Torre y Sevil } \\
(1625-1681)\end{array}$ & $\begin{array}{l}\text { Redon- } \\
\text { dilla }\end{array}$ \\
\hline CXXVI & Romance. & "Juanica, la mi Juanica" & $\begin{array}{l}\text { Jerónimo de Cáncer y Velas- } \\
\text { co }(: 1599 ?-1655)\end{array}$ & Romance \\
\hline CXXVII & $\begin{array}{l}\text { A una beata de la circunstan- } \\
\text { cia del soneto. }\end{array}$ & $\begin{array}{l}\text { "Por ser tan fea, a ser discreta } \\
\text { vino" }\end{array}$ & Gaspar de Figueroa ¿? & Soneto \\
\hline CXXVIII & $\begin{array}{l}\text { A una dama enferma de } \\
\text { calentura, con un ramo de } \\
\text { mosqueta, cogido después de } \\
\text { herido el sol. }\end{array}$ & "Ardió al sol la mariposa" & [De un grande ingenio] & Décima \\
\hline CXXIX & $\begin{array}{l}\text { Un galán requebrando un } \\
\text { cántaro, y responde él, que } \\
\text { está puesto en una ventana. }\end{array}$ & "Clérigo que un tiempo fui" & & Romance \\
\hline CXXX & $\begin{array}{l}\text { Soneto de dispares. Motejan- } \\
\text { do una mujer a un hombre. }\end{array}$ & $\begin{array}{l}\text { "Para pintarte, empiezo por la } \\
\text { boca" }\end{array}$ & & Soneto \\
\hline CXXXI & $\begin{array}{l}\text { Respuesta del galán a la } \\
\text { dama. }\end{array}$ & $\begin{array}{l}\text { "Es tal tu gracia, y aunque yo al } \\
\text { probarla" }\end{array}$ & & Soneto \\
\hline
\end{tabular}


El florilegio no parece seguir a priori un orden determinado a la hora de disponer los textos. Más de la mitad de las composiciones, en concreto 72 $(54,96 \%)$, son de cariz satírico o burlesco. Dentro de este bloque destacan 8 poemas $(6,1 \%)$, que reflejan enfrentamientos personales o literarios entre escritores de la época, siendo la querelle entre Góngora y Quevedo la más representada, con un total de 3 (2,29\%): el soneto X ("Anacreonte español, no hay quien os tope"); el XXII ("Si no sabéis, señora Cetina”); y el LII, que lleva por título "A un poeta corcovado, que se valió de trabajos ajenos de varios ingenios". Citaremos asimismo los poemas contra las costumbres del tiempo de los Austrias, aquellos otros que se burlan de defectos físicos, los que participan del encomio paradójico — como los dedicados a los mosquitos- y las fábulas burlescas. Por otro lado, el $45,04 \%$ de los restantes son de circunstancias, amorosos, o bien ceñidos al marbete de "ingeniosos". En conclusión, a grandes rasgos, la colectánea sobresale por su regusto chancero. Alfay recurrió a la burla, a la sátira, a la cotidianidad y al realismo como medios principales para atraerse el aplauso del vulgo, argucia común incluso en la práctica académica que "determinó el desarrollo de lo que se puede calificar como poesía familiar, casera o, por qué no, "aburguesada», en la que se manifiesta una amplia presencia del genus humile"27.

En consonancia con dicho tono, predomina el uso del octosílabo, cuyo principal cauce estrófico será el romance, usado hasta en 55 ocasiones $(41,9 \%)$. Le siguen las décimas, registradas en 19 composiciones $(14,5 \%)$, y las redondillas, con un total de 11 poemas $(8,3 \%)$. Meramente anecdótico es el uso de las quintillas, que solo se cuentan en 4 ocasiones (3\%) y de las coplas, empleadas apenas en 4 textos (3\%). Como apunta Bègue, se trata de formas estróficas "que podríamos calificar de "incomplejas", pues su extensión queda supeditada a la voluntad del autor ${ }^{28 ”}$, lo que sugiere la falta de concisión de los poetas de la

27 Alain Bègue, "Albores de un tiempo nuevo: la escritura poética de entre siglos (XVIIXVIII)", en La luz de la razón: literatura y cultura del siglo XVIII. A la memoria de Ernest Lluch, coords. Aurora Egido y José Enrique Laplana, Zaragoza, Instituto Fernando el Católico, 2010, pp. 97-121 (p. 49).

28 Ibidem, p. 46. Por lo general, según Alain Bègue, “Degeneración» y «prosaísmo» de la escritura poética de finales del siglo XVII y principios del XVIII: análisis de dos nociones heredadas", Criticón, 103-104 (2008), pp. 21-38, en esta época, "las 
segunda mitad del siglo XVII y de la primera mitad del Setecientos. No obstante, junto a esta marcada tendencia a la distensión, también encontraremos la concisión propia del soneto, estrofa representada hasta en 21 poemas (16\%) y que, como contrapunto del octosílabo, otorga variedad y riqueza a la antología. Detallamos a renglón seguido estos datos más pormenorizadamente:

\begin{tabular}{c:c:c}
\hline Estrofa & PoEMAS & PORCENTAJE \\
\hline Romances & 55 & $41,9 \%$ \\
\hline Sonetos & 21 & $16 \%$ \\
\hline Décimas & 19 & $14,5 \%$ \\
\hline Redondillas & 11 & $8,3 \%$ \\
\hline Quintillas & 4 & $3 \%$ \\
\hline Coplas & 4 & $3 \%$ \\
\hline Endechas & 4 & $3 \%$ \\
\hline Otros & 13 & $9,9 \%$ \\
\hline TOTAL & 131 & \\
\hline
\end{tabular}

Poesías varias de grandes ingenios españoles (1654). Formas métricas

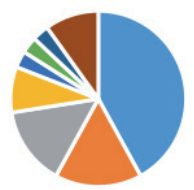

$\begin{array}{lll}\text { - Romances } & \text { - Sonetos } & \text { - Décimas } \\ \text { - Redondillas } & \text { - Quintillas } & \text { " Coplas } \\ \text { - Endechas } & \text { - Otros } & \end{array}$

Finalmente, por lo que atañe a los poetas seleccionados, Alfay muestra una clara preferencia por Góngora y la poética cultista, lo que constituye un reflejo de la poesía aragonesa del XVII. De acuerdo con Aurora Egido $^{29}$, los poetas aragoneses profesan temprano culto al autor cor-

composiciones adquieren una estructura abierta y, con la acumulación de conceptos, alcanzan fácilmente el centenar de versos" (p. 31).

29 Aurora Egido, "Apologistas y detractores", en La poesía aragonesa del siglo XVII (raíces culteranas), Zaragoza, Institución Fernando el Católico, 1979, pp. 9-60 (pp. 9-23). 
dobés. Tras la aparición del Polifemo y las Soledades en la primavera de 1613, se celebraron en Aragón una serie de justas poéticas en donde las referencias a Góngora son constantes. Nos referimos al Certamen por el traslado de las reliquias de San Ramón Nonat (Zaragoza, 1617), al dedicado a fray Luis de Aliaga (1619), al de la Cofradía de la Sangre de Cristo (1621) y al de la Virgen del Pilar (1628). Un año más tarde, se publicarían las Obras póstumas de Villamediana en Zaragoza, asentándose definitivamente el gusto por la poética gongorina. A Villamediana le siguió Matías de Aguirre, quien, en 1634, publicó las Navidades de Zaragoza $^{30}$, en donde incluye un largo poema cuya temática y forma emulan a las de las Soledades; Salcedo Coronel, quien en 1629 publicó su Polifemo comentado, completando entre 1636 y 1648 el comentario del resto de la obra gongorina; Miguel de Dicastillo, quien secundó el estilo de don Luis en su Aula de Dios (1643); Juan de Moncayo, en cuyas Rimas (1652) son más que evidentes los ecos gongorinos; Díez y Foncalda, quien con sus Poesías (1654) se sitúa en la estela del andaluz; y José Navarro, seguidor proclamado del cordobés, que dio a la estampa en 1654 sus Poesias varias, entre otros ${ }^{31}$. No obstante, su principal defensor fue Andrés Uztarroz, quien, si bien en un principio defendía el magisterio mixto de Góngora y los Argensola, ya en 1634 proclamó con vehemencia la supremacía absoluta de don Luis en una carta dirigida desde la Puebla de Montalbán ${ }^{32}$. Asimismo, alabará al cordobés en su Defensa de la patria del invencible mártir San Laurencio (1638), en su

30 La obra ha sido editada por María Pilar Sánchez Laílla, Edición y estudio de la "Navidad de Zaragoza" (1654) de Matías Aguirre, tesis doctoral dirigida por José Enrique Laplana Gil, Zaragoza, Universidad de Zaragoza, 2015.

31 Véase Almudena Vidorreta Torres, Estudio y edición de las "Poesías varias" de José Navarro (1654), tesis doctoral dirigida por Aurora Egido Martínez, Zaragoza, Universidad de Zaragoza, 2014.

32 En 1632 Uztarroz se había declarado seguidor a ultranza de la poética gongorina en su Defensa de la poesía española, respondiendo a un discurso de don Francisco de Quevedo que se halla en el principio de las "Rimas" del padre maestro Fray Luis de León. Tan solo un ańo después, en 1633, ratificaría su postura en el Antídoto contra la "Aguja de navegar cultos". No se conservan, empero, los manuscritos de ambas obras. Véase Robert Jammes, "Apéndice II. La polémica de las Soledades (1613-1666)” en Luis de Góngora y Argote, Soledades, ed. Robert Jammes, Madrid, Castalia, 1994, pp. 607-720 (p. 693). 


\section{Historia de Santo Domingo de Val (1643) y en los Progresos de la historia (1680).}

Con tales antecedentes, no resulta extraño que Góngora sea el poeta más representado en las Poesias varias con 19 composiciones (14,5\%), algunas de las cuales aparecen bajo el signo del anonimato en el florilegio, como es el caso de la XI, "A una mujer que, siendo muy puerca, presumía que la querían por hermosa”. Antonio Hurtado de Mendoza, con 12 (9,1\%), Francisco de la Torre y Sevil, con 7 (5,3\%) y Quevedo, representado con un total de $6(4,5 \%)$, quedan muy de lejos al autor de las Soledades:

\begin{tabular}{|c|c|c|c|c|c|}
\hline Autor & $\begin{array}{l}\text { COMPOSICIONES } \\
\text { DEL AUTOR }\end{array}$ & Porcentajes & Autor & Composiciones & Porcentajes \\
\hline $\begin{array}{l}\text { Luis de Góngora y } \\
\text { Argote }\end{array}$ & 19 & $14,5 \%$ & Padre Pineda & 1 & $0,7 \%$ \\
\hline $\begin{array}{l}\text { Antonio Hurtado } \\
\text { de Mendoza }\end{array}$ & 12 & $9,1 \%$ & $\begin{array}{l}\text { Diego Hurtado de } \\
\text { Mendoza }\end{array}$ & 1 & $0,7 \%$ \\
\hline $\begin{array}{l}\text { Francisco de la } \\
\text { Torre y Sevil }\end{array}$ & 7 & $5,3 \%$ & $\begin{array}{l}\text { Juan de Horozco y } \\
\text { Covarrubias }\end{array}$ & 1 & $0,7 \%$ \\
\hline $\begin{array}{l}\text { Francisco de } \\
\text { Quevedo y Villegas }\end{array}$ & 6 & $4,5 \%$ & $\begin{array}{l}\text { Jerónimo de } \\
\text { Villayzán }\end{array}$ & 1 & $0,7 \%$ \\
\hline García de Porras & 4 & $3 \%$ & $\begin{array}{l}\text { Regidor Juan } \\
\text { Fernández }\end{array}$ & 1 & $0,7 \%$ \\
\hline $\begin{array}{l}\text { Jerónimo de } \\
\text { Cáncer y Velasco }\end{array}$ & 3 & $2,2 \%$ & José de Zaporta & 1 & $0,7 \%$ \\
\hline $\begin{array}{l}\text { Miguel de } \\
\text { Cervantes }\end{array}$ & 2 & $1,5 \%$ & Pedro Panzano & 1 & $0,7 \%$ \\
\hline Gabriel Bocángel & 2 & $1,5 \%$ & Pedro de Castro & 1 & $0,7 \%$ \\
\hline Lope de Vega & 2 & $1,5 \%$ & $\begin{array}{l}\text { Alberto Díez de } \\
\text { Foncalda }\end{array}$ & 1 & $0,7 \%$ \\
\hline $\begin{array}{l}\text { Valentín de } \\
\text { Céspedes }\end{array}$ & 2 & $1,5 \%$ & Antonio Cohelo & 1 & $0,7 \%$ \\
\hline $\begin{array}{l}\text { Alonso Jerónimo } \\
\text { Salas Barbadillo }\end{array}$ & 2 & $1,5 \%$ & Pantaleón de Ribera & 1 & $0,7 \%$ \\
\hline Otros & 22 & $16,7 \%$ & Gaspar de Figueroa & 1 & $0,7 \%$ \\
\hline Anónimos & 48 & $36,6 \%$ & Alonso de Ledesma & 1 & $0,7 \%$ \\
\hline \multirow[t]{9}{*}{ TOTAL } & \multirow[t]{9}{*}{131} & & $\begin{array}{l}\text { Bartolomé Juan } \\
\text { Leonardo de Argensola }\end{array}$ & 1 & $0,7 \%$ \\
\hline & & & $\begin{array}{l}\text { Juan Pérez de } \\
\text { Montalbán }\end{array}$ & 1 & $0,7 \%$ \\
\hline & & & Francisco de Sayas & 1 & $0,7 \%$ \\
\hline & & & Diego Morlanés & 1 & $0,7 \%$ \\
\hline & & & Gaspar de Sotelo & 1 & $0,7 \%$ \\
\hline & & & Vélez de Guevara & 1 & $0,7 \%$ \\
\hline & & & $\begin{array}{l}\text { Antonio de Solís y } \\
\text { Rivadeneyra }\end{array}$ & 1 & $0,7 \%$ \\
\hline & & & Antonio Cuello & 1 & $0,7 \%$ \\
\hline & & & AA.VV. & 1 & $0,7 \%$ \\
\hline
\end{tabular}




\section{Poesios worios (1654) Autores}
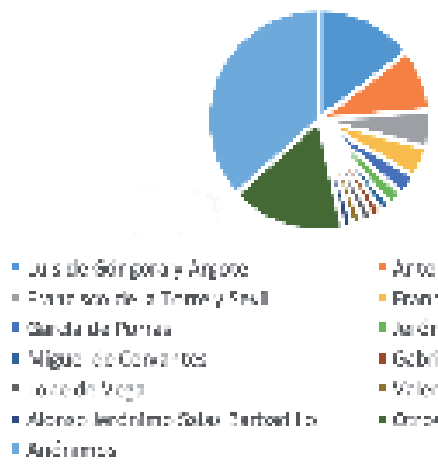

- suceria dekionicas

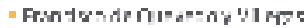

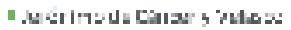

- Gibict Bowaze

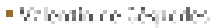

- orser

Finalmente, la influencia de Góngora se vislumbra incluso en aquellas composiciones que, o bien aparecen anónimas - pero conocemos su autor en la actualidad_- o bien son decididamente anónimas, las cuales suponen una parte importante de las Poesías varias:

\begin{tabular}{|c|c|c|}
\hline \multicolumn{3}{|c|}{ Porcentajes de atribuciones. Poesías varias ( 1654 ) } \\
\hline Número de composiciones atribuidas & 80 & $61,06 \%$ \\
\hline Número de composiciones sin atribuir y/o anónimas & 51 & $38,93 \%$ \\
\hline
\end{tabular}

\section{Poesías varias (1654). Composiciones des/atribuidas}

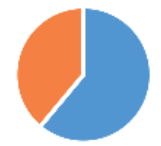

- Número de composiciones atribuidas

- Número de composiciones sin atribuir

Frente a las Poesías varias, la disposición textual de las Delicias de Apolo se estructura conforme a la temática de los poemas, que, al contrario de lo que sucede en el volumen anterior, resulta mucho más homogénea. Sombreamos los 30 poemas que se reciclan de las Poesías varias: 


\begin{tabular}{|c|c|c|c|c|}
\hline \multicolumn{5}{|c|}{$\begin{array}{l}\text { Delicias de Apolo, recreaciones del Parnaso, por las tres musas Urania, Euterpe y Caliope. } \\
\text { Hechas de varias poesias de los mejores ingenios de España (Zaragoza-Madrid, 1670) }\end{array}$} \\
\hline No & Título & Primer Verso & AUTOR & MÉTRICA \\
\hline \multicolumn{5}{|c|}{ Musa Urania } \\
\hline I & A la vida de nuestra señora. & $\begin{array}{l}\text { "Luciente, fecunda } \\
\text { estrella" }\end{array}$ & $\begin{array}{l}\text { Antonio Hurtado de } \\
\text { Mendoza (1586-1644) }\end{array}$ & Romance \\
\hline II & $\begin{array}{l}\text { A la soledad de Nuestra Señora } \\
\text { de Balma. }\end{array}$ & $\begin{array}{l}\text { "Soledad, no hay } \\
\text { compañía" }\end{array}$ & $\begin{array}{l}\text { Antonio Hurtado de } \\
\text { Mendoza (1586-1644) }\end{array}$ & Décima \\
\hline III & $\begin{array}{l}\text { La mayor obra de Dios nuestro } \\
\text { señor, con varios puntos de } \\
\text { Astrología. }\end{array}$ & "Aquel divino pintor" & $\begin{array}{l}\text { Lope de Vega y Carpio } \\
(1562-1635)\end{array}$ & Romance \\
\hline IV & Soneto a la astrología. & $\begin{array}{l}\text { "De cielos y elementos } \\
\text { ordenado" }\end{array}$ & & Soneto \\
\hline $\mathrm{V}$ & $\begin{array}{l}\text { Discurriendo por el nacimiento, } \\
\text { vida y muerte de nuestro } \\
\text { redentor. }\end{array}$ & $\begin{array}{l}\text { "Entre las sueltas } \\
\text { escarchas" }\end{array}$ & $\begin{array}{l}\text { [De un grande ingenio } \\
\text { castellano] }\end{array}$ & Romance \\
\hline VI & Afectos divinos. & $\begin{array}{l}\text { "Con ver mudanzas, mi } \\
\text { Dios" }\end{array}$ & & Romance \\
\hline VII & Enseña el ensayo de la muerte. & $\begin{array}{l}\text { "Ya muero, Señor, ya } \\
\text { escucho" }\end{array}$ & $\begin{array}{l}\text { Antonio Gual y Oleza } \\
(1594-1655)\end{array}$ & Romance \\
\hline VIII & $\begin{array}{l}\text { De un hombre puesto en el } \\
\text { último trance de su vida, } \\
\text { hablando con un crucifijo. }\end{array}$ & $\begin{array}{l}\text { "Señor, ya estoy de } \\
\text { partida" }\end{array}$ & & Romance \\
\hline IX & $\begin{array}{l}\text { Canta lágrimas eternas y afectos } \\
\text { de un corazón puesto en Dios } \\
\text { nuestro señor. }\end{array}$ & $\begin{array}{l}\text { "De mis ardientes } \\
\text { suspiros" }\end{array}$ & $\begin{array}{l}\text { José Lucio Espinosa } \\
\text { y Malo (1646-1691) } \\
\text { [compuesto en realidad } \\
\text { por Félix Lucio Espinosa } \\
\text { y Malo. Posible lapsus } \\
\text { calami] }\end{array}$ & Romance \\
\hline $\mathrm{X}$ & [Sin título] & $\begin{array}{l}\text { "De las culpas, Señor, } \\
\text { que he cometido" }\end{array}$ & & Soneto \\
\hline XI & $\begin{array}{l}\text { Al excelentísimo señor Duque de } \\
\text { Gandía. }\end{array}$ & "Suba el ingenio veloz" & & Romance \\
\hline XII & & $\begin{array}{l}\text { "Cansada Urania del } \\
\text { Divino canto" }\end{array}$ & & \\
\hline \multicolumn{5}{|c|}{ Musa Euterpe } \\
\hline XIII & Fábula de Mirra. & $\begin{array}{l}\text { "Canto de amor los } \\
\text { horrores" }\end{array}$ & $\begin{array}{l}\text { Valentín de Céspedes } \\
(1595-1668)\end{array}$ & Romance \\
\hline XIV & $\begin{array}{l}\text { A una dama que por dar su } \\
\text { retrato a un galán le dio una } \\
\text { lámina en que estaba grabado el } \\
\text { de la muerte. }\end{array}$ & "Trocaste tu efigie, Lisi" & $\begin{array}{l}\text { Manuel de Buitrago y } \\
\text { Zayas ?? }\end{array}$ & Romance \\
\hline $\mathrm{XV}$ & Fábula de Adonis. & $\begin{array}{l}\text { " } \mathrm{OH} \text {, dulce honor de mi } \\
\text { pluma" }\end{array}$ & Diego de Frías ¿? & Romance \\
\hline XVI & Romance. & "Juanica, la mi Juanica" & $\begin{array}{l}\text { Jerónimo de Cáncer y } \\
\text { Velasco (¿1599?-1655) }\end{array}$ & Romance \\
\hline XVII & Romance amoroso. & $\begin{array}{l}\text { "La gala de la } \\
\text { hermosura" }\end{array}$ & $\begin{array}{l}\text { Antonio Hurtado de } \\
\text { Mendoza (1586-1644) } \\
\text { Atribuido erróneamente }\end{array}$ & Romance \\
\hline XVIII & A una dama. & $\begin{array}{l}\text { “¿No me conocéis, } \\
\text { serranos?” }\end{array}$ & $\begin{array}{l}\text { a Pedro Calderón. } \\
\text { Compuesto por, García } \\
\text { de Porras ?? }\end{array}$ & Romance \\
\hline XIX & Endechas líricas. & $\begin{array}{l}\text { "Pastores, ;que me } \\
\text { abraso!" }\end{array}$ & $\begin{array}{l}\text { Antonio Hurtado de } \\
\text { Mendoza (1586-1644) }\end{array}$ & Endechas \\
\hline $\mathrm{XX}$ & Romance amoroso. & "En la mudanza de Gila" & $\begin{array}{l}\text { Antonio Hurtado de } \\
\text { Mendoza (1586-1644) }\end{array}$ & Romance \\
\hline
\end{tabular}




\begin{tabular}{|c|c|c|c|c|}
\hline XXI & Letrilla amorosa. & "Paloma era mi querida" & Atribuido a Luis de & ¿? \\
\hline XXII & A una dama. & $\begin{array}{l}\text { "La bella deidad del } \\
\text { Tajo" }\end{array}$ & $\begin{array}{l}\text { [Luis de Góngora } \\
\text { (1561-1627)] }\end{array}$ & Romance \\
\hline XXIII & A la fortuna. & "Juráralo yo, Fortuna” & $\begin{array}{l}\text { Anastasio Pantaleón de } \\
\text { Ribera (1600-1629) }\end{array}$ & Romance \\
\hline XXIV & Al retrato de otra Julia. & "Allá va de mi cielo" & & $\begin{array}{l}\text { Seguidi- } \\
\text { llas }\end{array}$ \\
\hline XXV & $\begin{array}{l}\text { A la fiesta de los toros que hubo } \\
\text { en Madrid a los años de la } \\
\text { Reina, mi Señora. }\end{array}$ & $\begin{array}{l}\text { "Gran héroe, duque de } \\
\text { Sessa” }\end{array}$ & $\begin{array}{l}\text { Gabriel Bocángel (1603- } \\
\text { 1658) }\end{array}$ & Romance \\
\hline XXVI & $\begin{array}{l}\text { Pregunta Fabio a Menandro } \\
\text { cómo se portara con su dama, a } \\
\text { quien no puede o no sabe obligar } \\
\text { con finezas, y este le aconseja así. }\end{array}$ & $\begin{array}{l}\text { "Pídesme consejo en } \\
\text { caso" }\end{array}$ & & Romance \\
\hline XXVII & $\begin{array}{l}\text { Consejos para la Corte y la } \\
\text { Universidad de Bolonia. }\end{array}$ & $\begin{array}{l}\text { "Mas ya que del tosco } \\
\text { traje" }\end{array}$ & $\begin{array}{l}\text { Juan de Matos Fragoso } \\
(1608-1689)\end{array}$ & Romance \\
\hline XXVIII & $\begin{array}{l}\text { De don Gabriel de Bocángel, } \\
\text { hallándose en su amor obstinado } \\
\text { a muchos desengaños. }\end{array}$ & "Pastor mal afortunado" & $\begin{array}{l}\text { Gabriel Bocángel (1603- } \\
\text { 1658) }\end{array}$ & Romance \\
\hline XXIX & $\begin{array}{l}\text { Retrato de una dama que por } \\
\text { bella y entendida se equivocaba } \\
\text { lo insigne. }\end{array}$ & "Anarda, va de retrato" & $\begin{array}{l}\text { Gabriel Bocángel (1603- } \\
\text { 1658) }\end{array}$ & Romance \\
\hline XXX & $\begin{array}{l}\text { Deposición amante de su } \\
\text { rendimiento. }\end{array}$ & $\begin{array}{l}\text { "Cautiváronme dos } \\
\text { ojos" }\end{array}$ & $\begin{array}{l}\text { Gabriel Bocángel (1603- } \\
\text { 1658) }\end{array}$ & Romance \\
\hline XXXI & $\begin{array}{l}\text { A una dama que, queriendo ser } \\
\text { tercera de otro, enamoró a un } \\
\text { hombre. }\end{array}$ & $\begin{array}{l}\text { "Bien el corazón, } \\
\text { seńora" }\end{array}$ & $\begin{array}{l}\text { Gabriel Bocángel (1603- } \\
\text { 1658) }\end{array}$ & Romance \\
\hline XXXII & $\begin{array}{l}\text { A Filis llorando una ausencia de } \\
\text { su amante. }\end{array}$ & "Perlas lloraba la niña" & $\begin{array}{l}\text { Gabriel Bocángel (1603- } \\
\text { 1658) }\end{array}$ & Romance \\
\hline XXXIII & $\begin{array}{l}\text { Pide una dama celos a su } \\
\text { amante, al tiempo que él, o } \\
\text { acaso, o de industria, la dio un } \\
\text { ramillete de violetas azules. }\end{array}$ & $\begin{array}{l}\text { "Notaba Angélica un } \\
\text { día" }\end{array}$ & & Romance \\
\hline XXXIV & $\begin{array}{l}\text { En la muerte de una dama, } \\
\text { cuya edad temprana y méritos } \\
\text { de virtud y belleza empeñaron } \\
\text { mucho la común lástima. }\end{array}$ & $\begin{array}{l}\text { "¿A dónde está el sol del } \\
\text { prado?” }\end{array}$ & $\begin{array}{l}\text { Gabriel Bocángel (1603- } \\
1658 \text { ) }\end{array}$ & Romance \\
\hline XXXV & $\begin{array}{l}\text { A una dama que falta a tomar } \\
\text { el acero, viéndola su amante } \\
\text { recobrado el color. }\end{array}$ & $\begin{array}{l}\text { "Camina en tu breve } \\
\text { esfera" }\end{array}$ & Antonio Cuello ¿? & Romance \\
\hline XXXVI & $\begin{array}{l}\text { Canta el retrato de una } \\
\text { hermosura. }\end{array}$ & $\begin{array}{l}\text { "La flota que de Indias } \\
\text { vino" }\end{array}$ & $\begin{array}{l}\text { Atribuido erróneamente } \\
\text { a Francisco de Quevedo } \\
\text { (1580-1645). En las } \\
\text { Poesías varias atribuido a } \\
\text { Luis de Góngora (1561- } \\
\text { 1627) }\end{array}$ & Romance \\
\hline XXXVII & Letrilla que se cantó en Palacio. & $\begin{array}{l}\text { "Porque está llorando } \\
\text { el alba" }\end{array}$ & & Romance \\
\hline XXXVIII & El pastor Belardo a Lucinda. & "Famoso Guadalquivir" & $\begin{array}{l}\text { [Lope de Vega y Carpio } \\
\text { (1562-1635)] } \\
\text { Atribuido erróneamente }\end{array}$ & Romance \\
\hline XXXIX & Romance a una dama. & $\begin{array}{l}\text { "Saca el Oriente a la } \\
\text { Aurora" }\end{array}$ & $\begin{array}{l}\text { a Juan de Zabaleta. } \\
\text { Compuesto por García } \\
\text { de Porras ?? }\end{array}$ & Romance \\
\hline XL & Dido y Eneas. & "El fugitivo troyano" & $\begin{array}{l}\text { Alonso Jerónimo Salas } \\
\text { de Barbadillo (1581- } \\
\text { 1635) }\end{array}$ & Romance \\
\hline
\end{tabular}




\begin{tabular}{|c|c|c|c|c|}
\hline XLI & Fábula de Atalanta. & $\begin{array}{l}\text { "Esquiva, Atalanta } \\
\text { siempre" }\end{array}$ & $\begin{array}{l}\text { Atribuido erróneamente } \\
\text { a Agustín de Moreto. } \\
\text { Compuesto por Valentín } \\
\text { de Céspedes (1595- } \\
1668 \text { ) }\end{array}$ & Romance \\
\hline XLII & Fábula de Apolo y Dafne. & $\begin{array}{l}\text { "Aquel dios ciego y } \\
\text { malsín" }\end{array}$ & $\begin{array}{l}\text { Atribuida erróneamente } \\
\text { a Jerónimo de Cáncer y } \\
\text { Velasco. Compuesto por } \\
\text { Salas de Barbadillo }\end{array}$ & Romance \\
\hline XLIII & $\begin{array}{l}\text { Euterpe canta a un luto de una } \\
\text { dama. }\end{array}$ & $\begin{array}{l}\text { "La beldad más } \\
\text { peregrina" }\end{array}$ & $\begin{array}{l}\text { Atribuido erróneamente } \\
\text { a Román Montero. } \\
\text { Compuesto por Diego } \\
\text { Morlanés ?? }\end{array}$ & Romance \\
\hline XLIV & A un rio helado. & $\begin{array}{l}\text { "Salid, ;oh, Clori } \\
\text { divina!" }\end{array}$ & $\begin{array}{l}\text { Atribuido erróneamente } \\
\text { a Pedro Calderón } \\
\text { Compuesto por García } \\
\text { de Porras ? }\end{array}$ & Romance \\
\hline XLV & A unos ojos negros. & $\begin{array}{l}\text { "Ojos, de cuyo } \\
\text { esplendor" }\end{array}$ & $\begin{array}{l}\text { Jerónimo de Cáncer y } \\
\text { Velasco (¿1599?-1655) }\end{array}$ & Décimas \\
\hline XLVI & $\begin{array}{l}\text { De don Antonio de Mendoza, } \\
\text { probando ser mejor desgraciado } \\
\text { discreto que necio virtuoso. }\end{array}$ & $\begin{array}{l}\text { "Si el necio, aunque } \\
\text { afortunado" }\end{array}$ & $\begin{array}{l}\text { Antonio Hurtado de } \\
\text { Mendoza (1586-1644) }\end{array}$ & Décima \\
\hline XLVII & Del mismo, prueba lo contrario. & $\begin{array}{l}\text { "Una perpetua } \\
\text { esperanza" }\end{array}$ & $\begin{array}{l}\text { Antonio Hurtado de } \\
\text { Mendoza (1586-1644) }\end{array}$ & Décima \\
\hline XLVIII & $\begin{array}{l}\text { El mismo prueba contra lo uno } \\
\text { y lo otro. }\end{array}$ & "El que no llega a saber" & $\begin{array}{l}\text { Antonio Hurtado de } \\
\text { Mendoza (1586-1644) }\end{array}$ & Décima \\
\hline XLIX & Romance. & "En las orillas del Tajo" & $\begin{array}{l}\text { Luis de Góngora (1561- } \\
1627 \text { ) }\end{array}$ & Romance \\
\hline $\mathrm{L}$ & Fábula de Júpiter y Europa. & $\begin{array}{l}\text { "Nació Europa, ninfa } \\
\text { bella" }\end{array}$ & José Zaporta ¿? & Décimas \\
\hline LI & $\begin{array}{l}\text { En memoria de haber visto } \\
\text { a Floris entre las flores de un } \\
\text { hermoso jardin. }\end{array}$ & "Salió Floris una tarde" & & Romance \\
\hline LII & $\begin{array}{l}\text { Descubre Euterpe la Calle } \\
\text { Mayor de Madrid el día de San } \\
\text { Miguel. }\end{array}$ & "En el golfo de Madrid" & & Romance \\
\hline LIII & Fábula de Alfeo y Aretusa. & "Al cleoneo león" & $\begin{array}{l}\text { [Anastasio Pantaleón de } \\
\text { Ribera (1600-1629)] }\end{array}$ & Romance \\
\hline LIV & $\begin{array}{l}\text { Alabanza de la hermosísima } \\
\text { Laurencia. }\end{array}$ & $\begin{array}{l}\text { "Cuando sale el alba } \\
\text { hermosa" }\end{array}$ & $\begin{array}{l}\text { [Lope de Vega y Carpio } \\
(1562-1635)]\end{array}$ & Romance \\
\hline LV & $\begin{array}{l}\text { Pinta las prendas de una dama } \\
\text { disfrazada con el nombre de } \\
\text { Cloris. }\end{array}$ & $\begin{array}{l}\text { "Pastores de } \\
\text { Manzanares" }\end{array}$ & & Romance \\
\hline LVI & $\begin{array}{l}\text { A la misma, habiéndola } \\
\text { visto descalza bañarse en } \\
\text { Manzanares. }\end{array}$ & $\begin{array}{l}\text { "Por márgenes de } \\
\text { esmeralda" }\end{array}$ & & Romance \\
\hline LVII & Endechas. & $\begin{array}{l}\text { "Junto a una fuente } \\
\text { clara" }\end{array}$ & $\begin{array}{l}\text { Luis de Góngora (1561- } \\
\text { 1627) }\end{array}$ & Endechas \\
\hline LVIII & Coro del ejemplo. & "Este fin a tus desvelos" & & Sextillas \\
\hline LIX & & "Euterpe, que sonora" & & \\
\hline \multicolumn{5}{|c|}{ Musa Calíope } \\
\hline LX & $\begin{array}{l}\text { Elogio a la constancia, valor y } \\
\text { piedad de la Majestad Católica } \\
\text { del Rey, Nuestro Señor, Filipo } \\
\text { el Grande. En el sitio y entrega } \\
\text { de Lérida. }\end{array}$ & $\begin{array}{l}\text { "Estos de mi tarda } \\
\text { pluma" }\end{array}$ & $\begin{array}{l}\text { Juan Lorenzo Ibáńez de } \\
\text { Aoyz ¿? }\end{array}$ & Romance \\
\hline
\end{tabular}




\begin{tabular}{|c|c|c|c|c|}
\hline LXI & Romance. & $\begin{array}{l}\text { "Generoso don } \\
\text { Antonio" }\end{array}$ & $\begin{array}{l}\text { Vicente Sánchez (1643- } \\
1680)\end{array}$ & Romance \\
\hline LXII & $\begin{array}{l}\text { A su alteza el serenisimo } \\
\text { señor fon Juan de Austria, } \\
\text { contemplándole rayo de la } \\
\text { guerra y luz de la paz. }\end{array}$ & $\begin{array}{l}\text { "Del héroe más } \\
\text { soberano" }\end{array}$ & $\begin{array}{l}\text { [De un genio de esta } \\
\text { ciudad] }\end{array}$ & Romance \\
\hline LXIII & Romance. & $\begin{array}{l}\text { "Zaragoza, aquel } \\
\text { emporio" }\end{array}$ & $\begin{array}{l}\text { José Tafalla y Negrete } \\
(1636-1696)\end{array}$ & \\
\hline LXIV & $\begin{array}{l}\text { Lágrimas de Escipión Africano, } \\
\text { en la ruina de Numancia. }\end{array}$ & "Aquella ciudad famosa" & $\begin{array}{l}\text { Francisco de Pinel y } \\
\text { Monroy ?? }\end{array}$ & Romance \\
\hline LXV & A Céspedes el bravo. & $\begin{array}{l}\text { "Esta imitación de } \\
\text { Marte" }\end{array}$ & & Romance \\
\hline LXVI & Al valeroso Céspedes. & $\begin{array}{l}\text { "Ese mármol que } \\
\text { respira" }\end{array}$ & $\begin{array}{l}\text { Juan de Matos Fragoso } \\
(1608-1689)\end{array}$ & $\begin{array}{l}\text { Romance } \\
\text { en ecos }\end{array}$ \\
\hline LXVII & $\begin{array}{l}\text { Suceso raro estando sitiada } \\
\text { Novara por los franceses. }\end{array}$ & $\begin{array}{l}\text { "Contra el campo } \\
\text { numeroso" }\end{array}$ & & Romance \\
\hline LXVIII & $\begin{array}{l}\text { Octavas heroicas al Rey, nuestro } \\
\text { señor Carlos II. }\end{array}$ & $\begin{array}{l}\text { "Si entre las luces del } \\
\text { primer agrado" }\end{array}$ & & Octavas \\
\hline \multicolumn{5}{|c|}{ 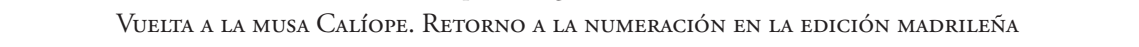 } \\
\hline LXIX & Al Rey, nuestro señor. & $\begin{array}{l}\text { "Hoy, pues, Carlos } \\
\text { heroico, que el dichoso" }\end{array}$ & & Octavas \\
\hline LXX & & "Así, a lo sonoro" & & \\
\hline LXXI & $\begin{array}{l}\text { Al serenisimo señor don Juan de } \\
\text { Austria. }\end{array}$ & $\begin{array}{l}\text { "Este, que a voz de grito } \\
\text {-;oh, Bulenquino!-"” }\end{array}$ & & Soneto \\
\hline
\end{tabular}

Musa Euterpe. Pliego inserto sin numerar.

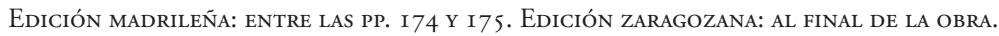

\begin{tabular}{c|l|l|l|l|} 
LXXII & $\begin{array}{l}\text { A los ojos de una hermosa } \\
\text { dama. }\end{array}$ & $\begin{array}{l}\text { "Ya no mata amor, } \\
\text { zagales" }\end{array}$ & $\begin{array}{l}\text { Agustín Moreto y } \\
\text { Cabaña (1618-1669) }\end{array}$ & Romance \\
\hline LXXIII & $\begin{array}{l}\text { Canta enseñando con voces } \\
\text { morales y políticas ser } \\
\text { cortesano discreto. }\end{array}$ & $\begin{array}{l}\text { Fernando" } \\
\text { Gabriel Bocángel (1603- } \\
1658)\end{array}$ & Romance \\
\hline LXXIV & $\begin{array}{l}\text { Consejos políticos para la } \\
\text { corte. Segunda parte. }\end{array}$ & $\begin{array}{l}\text { "A la corte vas, } \\
\text { Montano" }\end{array}$ & $\begin{array}{l}\text { Juan de Matos Fragoso } \\
(1608-1689)\end{array}$ & Romance \\
\hline
\end{tabular}

Las Delicias de Apolo ofrecen, por tanto, una dispositio más elaborada que la del florilegio de 1654. La división en musas de este volumen se aproxima a la que presentaba El Parnaso español, monte en dos cumbres dividido, con las nueve musas (1648) de Francisco de Quevedo, publicado póstumamente por José Antonio González de Salas, y que, curiosamente, también se completaría en 1670 con la publicación de Las tres musas últimas castellanas, en el haber de su sobrino Pedro Aldrete de Villegas ${ }^{33}$. Más signifi-

33 Véase Rodrigo Cacho Casal, "Quevedo y el canon poético español”, en El canon poético en el siglo XVII. IX Encuentro Internacional sobre Poesía del Siglo de Oro, coord. Begoña López Bueno, Sevilla, Universidad de Sevilla / Grupo PASO, 2010, pp. 421-452 (p. 446). 
cativo aún es que esta antología agrupe sus poemas bajo la advocación de las tres musas ausentes en el Parnaso español - a saber: Urania, Euterpe y Calíope-; de ahí que Ruiz Pérez considere que las Delicias podrían "ocupar el vacío dejado por González de Salas en la primera entrega del Parnaso" ${ }^{34}$. No obstante, aunque los 74 textos de las Delicias - 28 de ellos anónimos en la antología (37,8\%) — se distribuyen atendiendo a su temática, la disposición interna de cada uno de los tres bloques no parece plegarse a un esquema fijo: los poemas se suceden sin orden aparente, alternándose en la musa Euterpe, por ejemplo, los amorosos con los de circunstancias e incluso con los didáctico-morales, con independencia de sus respectivos autores. De esta forma, a la "Fábula de Mirra", de carácter culto, gentílico y amoroso, le sigue un poema de carácter moral: "A una dama que por dar su retrato a un galán le dio una lámina en que estaba grabado el de la muerte"; y a continuación nos topamos con la "Fábula de Adonis", de marcado perfil burlesco. No hay que ser muy avispado para darse cuenta de que el orden más lógico invitaría a reunir los siete epilios antologados: la Fábula de Mirra, de Valentín de Céspedes; la de Adonis, de Diego de Frías; Dido y Eneas, de Salas de Barbadillo; la Fábula de Atalanta —erróneamente atribuida a Agustín Moreto- de Valentín de Céspedes; la Fábula de Apolo y Dafne, también erróneamente atribuida a Jerónimo de Cáncer, que salió de la pluma de Salas de Barbadillo; la Fábula de Júpiter y Europa, de José de Zaporta; y, por último, la Fábula de Alfeo y Aretusa, de Anastasio Pantaleón. Más lógico aún sería colocar consecutivamente la Fábula de Mirra, la Fábula de Adonis y la Fábula de Atalanta, por su clara vinculación temática. No obstante, Alfay disemina los epilios aleatoriamente, interponiendo, por ejemplo, entre la Fábula de Adonis y el siguiente epilio, Dido y Eneas, un total de 24 poemas de muy diversa índole. Mucho más coherentes en su disposición son, empero, los bloques dedicados a Urania y Calíope, los cuales obedecen a una lógica editorial impecable.

34 Pedro Ruiz Pérez, "Entre dos Parnasos: poesía, institución y canon”, Criticón, 103104 (2008), pp. 207-237 (p. 211). 


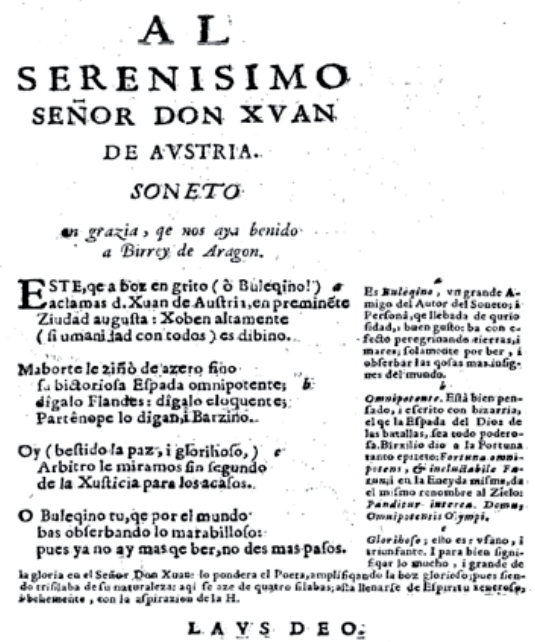

Fig. 7

Como ya apuntamos, se percibe, además, cierto descuido que no acusaban las Poesías varias y que, en ocasiones, afecta a la dispositio textual. Recordemos, sin ir más lejos, las cinco hojas sin paginar intercaladas entre las últimas páginas, en las que Alfay recupera la portada de la musa Euterpe, desluciendo así una ordenación que, a priori, se antojaba correcta. Temáticamente, contienen tres poemas muy dispares: junto a dos epístolas didácticas ("Canta enseñando con voces morales y políticas ser cortesano discreto", de Gabriel Bocángel y "Consejos políticos para la corte. Segunda parte", de Juan de Matos Fragoso) $)^{35}$, hallamos un poema amoroso ("A los ojos de una hermosa dama") de Agustín Moreto. No conviene olvidar que Alfay ya había incluido la primera parte de los "Consejos para la Corte y la Universidad de Bolonia" de Matos Fragoso con anterioridad, en las pp. 103-104, así como un sinfín de composiciones amorosas similares a la de Moreto. El motivo por el que estos

35 Rocío Jodar Jurado, "Cómo ser un buen cortesano en 1000 sencillos pasos: Gabriel Bocángel y Juan de Matos Fragoso en las Delicias de Apolo (José Alfay, Francisco de la Torre y Sevil, 1670)", en La corte del Barroco. Textos literarios, avisos, manuales de corte, etiqueta y oratoria, coords. Antonio Rey Hazas, Mariano de la Campa Gutiérrez, Esther Jiménez Pablo, Madrid, Ediciones Polifemo, 2016, pp. 589-632. 
textos se imprimen por separado nos es, por tanto, desconocido y no parece obedecer a ningún tipo de plan editorial, aunque resulta lógico pensar que llegaron a poder del editor ya iniciado el proceso de impresión. Siguiendo el orden correlativo, estas hojas tendrían que haberse encuadernado en la página 73, como apertura del bloque. No obstante, si aceptamos que la primera parte de los "Consejos para la corte" de Matos Fragoso debería disponerse con anterioridad a la segunda, entonces dicho pliego no podría incorporarse al inicio del bloque de la musa Euterpe, a pesar de la portada que lo precede. No obstante, el marbete "Segunda parte" podría hace referencia también al orden de llegada de los textos, lo que reforzaría nuestra hipótesis inicial.

Finalmente, el último poema que recopila la antología presenta obvias diferencias respecto al resto. Nos referimos al soneto "Al serenísimo señor don Juan de Austria” (Fig. 7), que, amén de presentar una tipografía distinta, incluye una serie de notas al margen.

Además de por su tipografía, este poema destaca también por su cauce estrófico: el soneto. De los 74 textos que componen esta antología, 55 son romances $(74,32 \%)$. Frente a ellos, tan solo se recogen 6 poemas escritos en décimas (8,1\%), 3 sonetos (4,05\%), 2 endechas $(2,7 \%)$ y 2 composiciones en octavas $(2,7 \%)$. Esporádicamente encontramos el uso de estrofas menos convencionales:

\begin{tabular}{c|c|c}
\hline Estrofas & $\begin{array}{c}\text { No DE } \\
\text { COMPOSICIONES }\end{array}$ & PORCENTAJE \\
\hline Romances & 55 & $74,32 \%$ \\
\hline Sonetos & 3 & $4,05 \%$ \\
\hline Décimas & 6 & $8,1 \%$ \\
\hline Octavas & 2 & $2,7 \%$ \\
\hline Endechas & 2 & $2,7 \%$ \\
\hline Otros & 6 & $8,1 \%$ \\
\hline TOTAL & 74 & \\
\hline
\end{tabular}

Delicias de Apolo (1670). Estrofas.

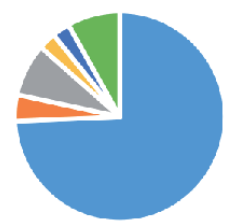

- Romances $=$ Sonetos $=$ Décimas

- Octavas - Endechas - Otros

En consecuencia, si ya las Poesias varias ofrecían una gama estrófica limitada, las Delicias de Apolo reducen ese abanico considerablemente, otor- 
gando la supremacía al octosílabo y al romance. No obstante, sí que se amplía el ramillete de autores recopilados: Góngora deja de ser el poeta mejor representado, con tan solo 5 poemas $(6,76 \%)$, frente a los 8 de Gabriel Bocángel y Antonio Hurtado de Mendoza. Con todo, la antología sigue evidenciando un marcado acento culto, siendo epígonos del racionero cordobés la mayoría de los poetas seleccionados, como Jerónimo de Cáncer y Velasco (representado con 3 poemas; 4,5\%) y Pantaleón de Ribera (con 3 poemas; 4,5\%).

\begin{tabular}{|c|c|c|c|c|}
\hline Autor & $\begin{array}{c}\text { Composiciones } \\
\text { del autor }\end{array}$ & Porcentaje & \multicolumn{2}{|c|}{ OTROS AUTORES } \\
\hline $\begin{array}{l}\text { Luis de Góngora y } \\
\text { Argote }\end{array}$ & 5 & $6,76 \%$ & Autor & COMPOSICIONES \\
\hline $\begin{array}{c}\text { Antonio Hurtado de } \\
\text { Mendoza }\end{array}$ & 8 & $10,81 \%$ & $\begin{array}{c}\text { Francisco de la Torre } \\
\text { y Sevil }\end{array}$ & 1 \\
\hline García de Porras & 3 & $4,05 \%$ & $\begin{array}{c}\text { José Lucio Espinosa } \\
\text { [Félix de Lucio Espinosa } \\
\text { y Malo] }\end{array}$ & 1 \\
\hline $\begin{array}{c}\text { Jerónimo de Cáncer y } \\
\text { Velasco }\end{array}$ & 2 & $2,70 \%$ & Diego Morlanés & 1 \\
\hline Gabriel Bocángel & 8 & $10,81 \%$ & $\begin{array}{c}\text { Antonio de Gual y } \\
\text { Oleza }\end{array}$ & 1 \\
\hline Lope de Vega & 3 & $4,05 \%$ & Diego de Frías & 1 \\
\hline Valentín de Céspedes & 2 & $2,70 \%$ & $\begin{array}{c}\text { Juan Lorenzo Ibáñez } \\
\text { Aoyz }\end{array}$ & 1 \\
\hline Pantaleón de Ribera & 3 & $4,05 \%$ & Víctor Sánchez & 1 \\
\hline $\begin{array}{l}\text { Alonso Jerónimo de } \\
\text { Salas Barbadillo }\end{array}$ & 2 & $2,70 \%$ & José Tafalla y Negrete & 1 \\
\hline Juan de Matos Fragoso & 2 & $2,70 \%$ & $\begin{array}{l}\text { Manuel de Buitrago y } \\
\text { Zayas }\end{array}$ & 1 \\
\hline OTROS & 12 & $16,22 \%$ & José Zaporta & 1 \\
\hline $\begin{array}{l}\text { Anónimos aún en la } \\
\text { actualidad }\end{array}$ & 24 & $31,08 \%$ & Antonio Cuello & 1 \\
\hline TOTAL & 74 & $100,00 \%$ & $\begin{array}{c}\text { Francisco de Pinel y } \\
\text { Monroy }\end{array}$ & 1 \\
\hline
\end{tabular}


Delicias de Apolo (1670). Autores

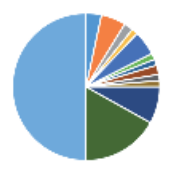

- Luis de Góngora y Argote
- García de Porras
- Gabriel Bocángel
- Valentín de Céspedes
- Alonso Jerónimo de Salas Barbadillo
- OTROS
- TOTAL

- Antonio Hurtado de Mendoza

= Jerónimo de Cáncer y Velasco

- Lope de Vega

- Pantaleón de Ribera

- Juan de Matos Fragoso

- Anónimos

Por último, un cierto descuido afecta también a varios textos erróneamente atribuidos. Nos referimos, en concreto, al poema XVIII, "Romance amoroso a una dama”, atribuido a Pedro Calderón, pero en realidad compuesto por García de Porras; al XLIII, "Euterpe canta a un luto de una dama” (titulado en las Poesías varias como "La beldad más peregrina”), atribuido a Román Montero, pero que salió de la pluma de Diego Morlanés; al poema XLIV, “A un río helado”, de nuevo atribuido a Calderón y escrito por García de Porras; al XXXIII, "La flota que de Indias vino”, atribuido a Quevedo, si bien escrito presuntamente por Góngora según las Poesías varias; al XLI, "Fábula de Atalanta”, atribuida a Agustín Moreto, pero compuesta por Valentín de Céspedes; y al poema XLII, "Fábula de Apolo y Dafne", en el haber de Salas de Barbadillo, aunque atribuida a Jerónimo de Cáncer. Asimismo, desciende ligeramente el porcentaje de composiciones sin atribuir y/o anónimas: del 38,93\% de las Poesias varias al 37,8\% de las Delicias de Apolo.

\begin{tabular}{|l|c|c|}
\hline \multicolumn{2}{|c|}{ Porcentajes de atribuciones. Delicias de Apolo $(1654)$} & \\
\hline Poemas anónimos en la antología & 28 & $37,8 \%$ \\
\hline Poemas erróneamente atribuidos & 7 & $9,4 \%$ \\
\hline Poemas bien atribuidos & 39 & $52,7 \%$ \\
\hline
\end{tabular}




\section{Delicias de Apolo (1670). Atribuciones y problemas autoriales}

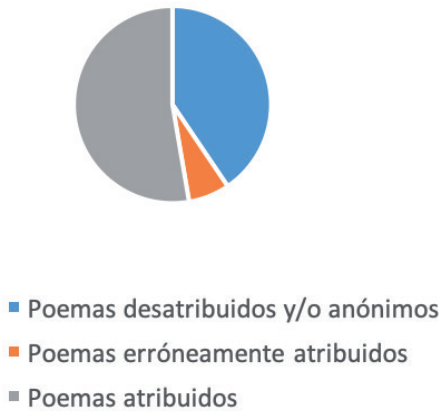

Según José Manuel Blecua ${ }^{36}$, estos errores de atribución podrían obedecer al hecho de que "Alfay quiso sin duda acrecentar el valor de su segunda selección suprimiendo nombres de poetas poco conocidos", lo que nos parece poco probable, puesto que disponía de suficientes textos de acreditadas figuras como para no tener que alterar la autoría de siete de ellos; un número, por otro lado, a todas luces insignificante en cuanto al total. No obstante, esta teoría sí que podría ajustarse al cambio temático que se percibe en la selección de los textos, muchos de los cuales, eso sí, son tomados directamente de las Poesías varias.

Amén del esquema compositivo y de sus posibles semejanzas con el Parnaso español, las similitudes de esta colección con las Poesías varias son más que evidentes. De un total de 74 poemas, $30(40,54 \%)$ ya habían sido incluidos en la colectánea previa. Todos los reincidentes se localizan en el bloque de la musa Euterpe, reservado para el canto de "humanas voces". Lo componen 50 textos, si atendemos al pliego sin numerar. Es decir, el 67,5\% de esta sección lo integran versos que Alfay ya había recogido en las Poesías varias. Si consideramos el carácter de los textos reciclados de su primer ramillete, comprobaremos enseguida que

36 José Manuel Blecua, "Introducción” a José Alfay (ed.), Poesías varias de grandes ingenios españoles, Zaragoza, Institución Fernando el Católico, 1946, pp. IX-XV (p. XIII). Sobre los errores de atribución, véanse también Miguel Romera-Navarro, "La antología de Alfay y Baltasar Gracián”, op. cit., y John M. Hill, “Notes on Alfay’s Poesías varias de grandes ingenios”, Revue hispanique, 56 (1922), pp. 423-433. 
las Delicias de Apolo reducen ostensiblemente la cantidad de los satíricoburlescos: de las 30 composiciones comunes a ambas colecciones, solo 4 (el 13,3\% de las reiteradas) poseen un marcado carácter burlesco, tratándose en casi todos los casos de fábulas mitológicas. Más en concreto: la "Fábula de Adonis", de Diego de Frías; "Dido y Eneas", de Salas de Barbadillo; "Fábula de Apolo y Dafne", de Salas de Barbadillo; y la "Fábula de Alfeo y Aretusa", de Anastasio Pantaleón de Ribera. A ellas hay que añadir el anónimo romance "Descubre Euterpe la Calle Mayor de Madrid el día de san Miguel”, sátira de estados que el zaragozano incorporó a esta colectánea.

Asimismo, Alfay elimina todos los poemas relativos a las rivalidades entre Góngora y sus impugnadores - especialmente los textos de Quevedo- - un indicio de que, a la altura de 1670 , se trataba de una querella extinta, si es que alguna vez fue tan cruda como nos la han pintado ${ }^{37}$. De este modo, la mayoría de los poemas espigados del volumen de 1654 presentan un cariz amoroso de tono idealista, lo que contrasta con el otro volumen de Alfay, en el que las notas satíricas son la tónica predominante. De los 30 poemas repetidos, 21 son de asunto amoroso, o lo que es lo mismo, un $70 \%$ de los reciclados. Esta tendencia idealista reincide en el conjunto del bloque dedicado a Euterpe, pues, de un total de 50 composiciones, 30 cantan las bondades de doncellas y damas de todo tipo. Es decir, un $75 \%$ de la sección relativa a la musa de la música y un $40,5 \%$ del total del libro. Dicho apartado se completa con 2 poemas de circunstancias - "En la muerte de una dama cuya edad temprana y méritos de virtud y belleza empeñaron mucho la común lástima”, de Gabriel Bocángel; y "Descubre Euterpe la Calle Mayor de Madrid el día de san

37 Según Antonio Carreira "Quevedo en la redoma: análisis de un fenómeno criptopoético", en Quevedo a nueva luz: escritura y politica, coords. Antonio Carreira y Lía Schwartz, Málaga, Universidad de Málaga, 1997, pp. 231-247 (pp. 233-234 y 247), ambos ingenios apenas coincidieron en vida. Además, el joven Quevedo no pudo competir con la fama del racionero cordobés debido al escaso número de poemas que publicó en vida. Por su parte, Amelia de Paz, "Góngora... ¿y Quevedo?”, Criticón, 75 (1999), pp. 29-47, advirtió que Góngora apenas dedicó tres composiciones al vate madrileño, demostrando que los descalificativos registrados en ellas forman parte de la tradición literaria, por lo que "la inventio de los poemas dedicados por don Luis a Quevedo no parece, pues, muy personal. Eso sí: Góngora desarrolla esos lugares comunes con la agudeza que lo distingue” (p. 35). 
Miguel"; 3 epigramas de Antonio Hurtado de Mendoza - "Probando ser mejor desgraciado y discreto que necio venturoso", "Prueba lo contrario" y "El mismo prueba contra lo uno y lo otro"-; 4 didáctico-morales — "A una dama que por dar su retrato a un galán le dio una lámina en que estaba grabado el día de su muerte", de Manuel de Buitrago; "Consejos para la corte y universidad de Bolonia", de Juan de Matos Fragoso; "Canta enseñando con voces morales y políticas ser cortesano discreto", de Gabriel Bocángel; y "Consejos políticos para la corte. Segunda parte", de Juan de Matos Fragoso-; y 2 líricos - "A la Fortuna”, de Anastasio Pantaleón de Ribera, y "A un río helado", atribuido erróneamente a Calderón y compuesto en realidad por García de Porras.

Frente a las Poesías varias y a su espíritu decididamente satírico, Alfay parece querer dotar a esta colectánea de un carácter ejemplar y hasta mariano, patente desde el primero de los textos, "A la vida de nuestra señora", de Antonio de Mendoza, al que siguen 23 (11 poemas pertenecientes a la musa Urania y 12 a Calíope; de manera que ambos bloques se componen del mismo número de composiciones, doce en total) religiosos y épico-laudatorios, que circundan, respectivamente, a los 50 poemas "humanos" del bloque dedicado a Euterpe, cimentado sobre versos amorosos y didáctico-morales. Luego, Alfay dispone simétricamente los poemas, de modo que la estructura final sería la siguiente: 12 religiosos + 50 humanos (30 reiterados) +12 epidícticos. Por tanto, a pesar del aparente orden aleatorio, la distribución obedece a un esquema prefijado en el que las composiciones de carácter más elevado abrazan a las de tono medio; y si bien dentro de cada una de estas secciones los poemas parecen alternarse caprichosamente, desde una perspectiva global el orden textual cobra sentido.

Alfay parece subrayar tanto al principio como al final de esta antología su tono elevado, que choca directamente con el carácter festivo de la anterior. Asimismo, recupera el gusto por "la poesía grave y seria, tan elogiada siempre por los críticos", que caracterizaba a la obra de los hermanos Argensola, quienes, junto a Baltasar Gracián, marcaron el devenir de la poesía aragonesa del Barroco. 


\section{Conclusiones}

De todo lo anterior, extraemos a modo de resumen las siguientes ideas en torno a la génesis de las Delicias de Apolo:

a) Las relaciones que el librero José Alfay estableció con otros miembros del sector - como Francisco de la Torre o Baltasar Gracián- quedaron sobradamente reflejadas en la publicación de sus dos grandes antologías poéticas: las Poesías varias (1654) y las Delicias de Apolo (1670).

b) No obstante, pese a que tanto Gracián como Francisco de la Torre desempeñaron un papel principal en la publicación de ambas, lo cierto es que el diseño editorial de las Delicias de Apolo, así como el plan comercial para su publicación y posterior distribución, estuvieron liderados por el zaragozano, quien, versado en las artes del fraude, preparó una doble edición de la obra simultáneamente en Madrid y Zaragoza. Asimismo, con vistas a un posible mecenazgo, dedicaría la edición zaragozana al duque de Alba, diseñando con esmero varios ejemplares destinados a este prócer.

c) Por otro lado, el volumen se presenta como claro sucesor de las Poesías varias, colectánea de la cual tomó prestados treinta poemas: una estrategia habitual en la producción del zaragozano, quien ya en 1666 había publicado el Sarao de Aranjuez a partir de los remanentes de la Mojiganga del gusto (1662).

d) Sin embargo, Alfay no se conforma con reciclar los textos de su anterior florilegio, sino que rediseña la dispositio de las Delicias de Apolo a partir del modelo ofrecido por el Parnaso español de Quevedo, distribuyendo los poemas en tres bloques dedicados a las tres musas ausentes en dicho volumen: Urania, Euterpe y Calíope. Curiosamente, también en 1670 se publicaron Las tres musas últimas castellanas, a cargo de Pedro Aldrete de Villegas, por lo que bien podría conjeturarse que Alfay pretendía cubrir con sus Delicias de Apolo el vacío dejado por el Parnaso español.

e) A pesar de ello, el modelo poético propuesto por Alfay en las Delicias de Apolo dista lo suyo del ofrecido por el madrileño en su Parnaso 
español. No en vano, Alfay recopiló en su antología un buen número de textos de vates aragoneses — como Juan Lorenzo Ibáñez de Aoyz, José Tafalla y Negrete, Félix Lucio de Espinosa y Malo y Diego Morlanés - junto a composiciones de los principales poetas nacionales del momento —como Gabriel Bocángel o Antonio Hurtado de Mendoza-, esbozando así un nuevo canon en el que las letras aragonesas sobresalen y se reivindican dentro del panorama nacional. Esta amalgama de poetas nacionales y locales aseguraba, además, la buena acogida del florilegio por parte del público y, en consecuencia, unos pingües beneficios para el colector zaragozano.

f) Finalmente, Alfay dotó a este volumen de un fuste del que adolecía su predecesor - las Poesías varias - a través de la supresión de la mayoría de los textos satírico-burlescos y de la incorporación de poemas religiosos y épico-laudatorios. Dicho fuste se realza, asimismo, gracias a la disposición de los poemas, de tal forma que las composiciones religiosas se sitúan en primer lugar —en el bloque dedicado a la musa Urania_- la poesía amorosa y la de circunstancias ocupan el centro del volumen - musa Euterpe-y, finalmente, en el último bloque — musa Calíope — se recogen los versos épico-laudatorios. 